\title{
A validation method for near-infrared spectroscopy based tissue oximeters for cerebral and somatic tissue oxygen saturation measurements
}

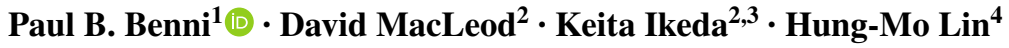

Received: 16 September 2016 / Accepted: 23 March 2017 / Published online: 3 April 2017

(C) The Author(s) 2017. This article is an open access publication

\begin{abstract}
We describe the validation methodology for the NIRS based FORE-SIGHT ELITE ${ }^{\circledR}$ (CAS Medical Systems, Inc., Branford, CT, USA) tissue oximeter for cerebral and somatic tissue oxygen saturation $\left(\mathrm{StO}_{2}\right)$ measurements for adult subjects submitted to the United States Food and Drug Administration (FDA) to obtain clearance for clinical use. This validation methodology evolved from a history of NIRS validations in the literature and FDA recommended use of Deming regression and bootstrapping statistical validation methods. For cerebral validation, forehead cerebral $\mathrm{StO}_{2}$ measurements were compared to a weighted 70:30 reference $\left(\mathrm{REF} \mathrm{CX}_{\mathrm{B}}\right)$ of co-oximeter internal jugular venous and arterial blood saturation of healthy adult subjects during a controlled hypoxia sequence, with a sensor placed on the forehead. For somatic validation, somatic $\mathrm{StO}_{2}$ measurements were compared to a weighted 70:30 reference $\left(\mathrm{REF} \mathrm{CX}_{\mathrm{S}}\right)$ of co-oximetry central venous and
\end{abstract}

The authors declare that this research study was conducted on human volunteers and complies with the ethical standards of the United States of America, the U. S. Federal Policy for the Protection of Human Subjects, (Common Rule, and subparts B, C, and D of the U. S. Health and Human Services regulations in 45CFR46), the Belmont Report, and Good Clinical Practice (GCP) guidelines.

Paul B. Benni

pbenni@ verizon.net

1 CAS Medical Systems (CASMED), Inc., Branford, CT, USA

2 Human Pharmacology \& Physiology Lab, Department of Anesthesiology, Duke University Medical Center, Durham, NC, USA

3 Department of Anesthesiology, University of Virginia, Charlottesville, VA, USA

4 Department of Population Health Science and Policy, Icahn School of Medicine at Mount Sinai, New York, NY, USA arterial saturation values following a similar protocol, with sensors place on the flank, quadriceps muscle, and calf muscle. With informed consent, 25 subjects successfully completed the cerebral validation study. The bias and precision (1 SD) of cerebral $\mathrm{StO}_{2}$ compared to REF CX $\mathrm{B}_{\mathrm{B}}$ was $-0.14 \pm 3.07 \%$. With informed consent, 24 subjects successfully completed the somatic validation study. The bias and precision of somatic $\mathrm{StO}_{2}$ compared to REF $\mathrm{CX}_{\mathrm{S}}$ was $0.04 \pm 4.22 \%$ from the average of flank, quadriceps, and calf $\mathrm{StO}_{2}$ measurements to best represent the global whole body REF $\mathrm{CX}_{\mathrm{S}}$. The NIRS validation methods presented potentially provide a reliable means to test NIRS monitors and qualify them for clinical use.

Keywords Tissue oximetry $\cdot$ Cerebral oximetry $\cdot$ Near Infrared Spectroscopy · NIRS · Tissue oxygen · Saturation · FDA

\section{Introduction}

The history of validations for tissue oxygen saturation $\left(\mathrm{StO}_{2}\right)$ measurements of the brain dates back to 1991 . McCormick et al. [1], first described the comparison of a Near-Infrared Spectroscopy (NIRS) monitor (INVOS ${ }^{\circledR}$ 2910, Somanetics Corp. acquired by Medtronic, Dublin, Ireland) to a mixed bed of arterial, venous, and capillary blood in the brain, using a weighted blood reference consisting of both arterial and venous blood. Pollard et al. [2] validated the first US FDA cleared commercial NIRS cerebral oximeter (INVOS ${ }^{\circledR} 3100$, Somanetics Inc., acquired by Medtronic, Dublin, Ireland) with a weighted blood co-oximetry reference of $0.75 \times$ jugular bulb oxygen saturation $\left(\mathrm{SjbO}_{2}\right)$ and $0.25 \times$ arterial oxygen saturation $\left(\mathrm{SaO}_{2}\right)[3,4]$. Henson et al. [5] and Shah et al. [6] followed with similar 
comparison studies with the INVOS 3100 monitor. Several years later, the first-generation FORE-SIGHT cerebral oximeter was validated against a cerebral blood weighted reference of $0.70 \times \mathrm{SjbO}_{2}$ and $0.30 \times \mathrm{SaO}_{2}$, [7-10], which was supported by PET studies by Ito, et al. [11] Other NIRS cerebral oximeter validations on both adult and pediatric subjects adopted the weighted 70:30 $\mathrm{SjbO}_{2}: \mathrm{SaO}_{2}$ reference [12-14].

For tissue oxygen saturation $\left(\mathrm{StO}_{2}\right)$ measurements of somatic (non-cerebral) locations, the reference used for NIRS monitor $\mathrm{StO}_{2}$ comparative and validation studies has been more varied and has included in-vitro comparisons. Research NIRS devices monitoring skeletal muscle were compared to a local venous oxygen saturation value from a blood draw during exercise [15-17]. The Hutchinson InSpectra ${ }^{\mathrm{TM}}$ (Hutchinson Technology Inc., Hutchinson, MN USA) was validated by comparing sensor measurements to blood saturation values in an in-vitro setup [18]. The ViOptix ODISsey ${ }^{\mathrm{TM}}$ (ViOptix, Inc, Fremont, CA USA) and Invos 3100 monitors were compared to co-oximetry measurements of blood draws on isolated animal limbs [19, 20]. For pediatrics, NIRS human somatic measurements were compared to central venous blood saturation values [21, 22]. Later, FORE-SIGHT pediatric somatic $\mathrm{StO}_{2}$ values were validated by comparing to a weighted blood cooximetry weighted blood co-oximetry reference of $0.70 \times$ central venous oxygen saturation $\left(\mathrm{ScvO}_{2}\right)$ and $0.30 \times$ arterial oxygen saturation $\left(\mathrm{SaO}_{2}\right)$ [23], which was supported by Pang et al. [24] from estimating whole body venous volume ratio.

The purpose of this paper is to describe one methodology of validating NIRS based tissue oximeters accepted by the US FDA for adult clinical clearance. For other world regulatory bodies such as the European Union Medical Device Directive (93/42/EEC) [25], there are similar requirements for clinical clearance of medical devices. This methodology of validating NIRS based tissue oximeters was used to obtain clinical clearance in the European Union, Canada, Australia, China, Japan, and Russia. Although industry methods of validation and FDA requirements have generally converged in the last two decades, there is no universally accepted reference to compare tissue oximeters against. The US FDA currently prefers oximeter validations, whether pulse oximeters, or tissue oximeters to be compared to a blood reference. The US FDA 510(K) medical device clearance method requires a reference to one or more similar function predicate devices that are validated similarly to the new medical device being evaluated. We present the methodology behind the validation of the second-generation FORE-SIGHT ${ }^{\circledR}$ tissue oximeter (FORE-SIGHT ELITE ${ }^{\circledR}$, CAS Medical Systems, Branford, CT USA) for both cerebral and somatic tissue oxygen saturation $\left(\mathrm{StO}_{2}\right)$ monitoring, with rationale behind the assumptions made, selection of a comparative reference, statistical methods used, subject recruitment requirements, particularly in terms of diverse skin tones, and regulatory requirements for clinical use. This NIRS validation methodology evolved from a history of NIRS-based tissue oximeter validation publications and FDA correspondence recommending use of Deming regression and bootstrap resampling techniques for analysis of comparative data to a reference. We will demonstrate how Deming regression and bootstrapping techniques are used to validate NIRS based tissue oximeters, and the potential advantages. Bootstrapping validation allows pooling of all subject data to a best fit model used to set algorithm parameters and then performing model validation. Previous NIRS validations relied on methods involving splitting the subjects to two groups, calibration set and test set, and/or using Bland-Altman in various forms.

\section{Methods}

\subsection{Technical and physiological background}

The methodology of NIRS based tissue oximeters are well explained elsewhere [26-36]. In short, tissue oxygen saturation $\left(\mathrm{StO}_{2}\right)$ measurements are based on the fact that oxyhemoglobin $\left(\mathrm{HbO}_{2}\right)$ and deoxyhemoglobin $(\mathrm{Hb})$ have different light absorption spectra. For brain, NIR light easily passes through skull bone and the absorption of NIR light by brain tissue is dependent upon chromophores (light absorbing tissue) within the path of the transmitted light in a highly optical scattering medium. $\mathrm{HbO}_{2}$ and $\mathrm{Hb}$ are the primary chromophores that absorb light, but background tissue light absorption can have a high impact on the measurement. Because biological tissue highly scatters light as well, reflectance type NIRS sensors can be used to target large organs such as the brain.

The first-generation FORE-SIGHT (CAS Medical Systems, Branford, CT USA) monitor was the second FDA cleared cerebral and somatic tissue oximeter to be widely available for clinical use in the USA, following the INVOS $^{\circledR}$ (Somanetics/Covidien, Boulder CO, USA) series of monitors. The first-generation FORE-SIGHT monitor used a laser light source with four discrete wavelengths $(690,780,805,850 \mathrm{~nm})$ compared to INVOS using two LED light source wavelengths (730 and $810 \mathrm{~nm}$ ). Besides accounting for $\mathrm{HbO}_{2}$ and $\mathrm{Hb}$, the extra wavelengths used in FORE-SIGHT allowed for compensation for tissue background optical properties such as skin pigmentation and deep tissue optical characteristics, which can be highly variable among different human subjects. The next generation FORE-SIGHT ELITE ${ }^{\circledR}$ tissue oximeter features a five wavelength LED light source $(685,730,770,805$, \& 
$870 \mathrm{~nm}$ ). The purpose of the extra fifth wavelength was to further improve compensation for tissue background optical properties, as well as reduce measurement error due to the LED's inherent wider spectral bandwidth. The algorithms used are based on a form of the Modified Beer-Lambert Law and are described elsewhere [7, 36, 37].

The monitor's adult Large sensors have two detectors (near and far), where the far detector is $5.0 \mathrm{~cm}$ and near detector is $1.5 \mathrm{~cm}$ from the light source. The $5 \mathrm{~cm}$ far detector optode separation was selected as a tradeoff of having sufficient signal to noise ratio of detected light and sampling a higher percentage of brain tissue both in depth and in volume compared to smaller optode separations [38-43]. The $1.5 \mathrm{~cm}$ near detector optode separation was selected to sample extracerebral tissues, while minimizing brain tissue sampling [39]. The signals from the near detector are effectively subtracted from the far detector to minimize effects of extracerebral interference from blood and skin pigmentation, as well as to compensate for light source variability in the calculation of $\mathrm{StO}_{2}$ by a variant of the commonly used NIRS spatially resolved spectroscopy (SRS) method [44-48]. However, under extreme manipulations to separate brain and extracerebral compartments, full extracerebral interference elimination is not achieved [49-51]. Skin pigmentation and deep tissue optical characteristics still need to be further compensated by the aforementioned addition of extra wavelengths. Because human scalp and skull thicknesses can vary considerably [52-55], the $5 \mathrm{~cm}$ far detector optode spacing better accommodates anatomical variations with the increased interrogation depth over smaller optode separations [39, 40, 56].

Because NIRS technology mainly interrogates the microvasculature of tissue, which includes arterioles, venules, and capillaries, and does not involve the pulsatile signal component, a NIRS tissue oxygen saturation $\left(\mathrm{StO}_{2}\right)$ measurement is made on a mixture of both venous and arterial blood. The general assumption used in our analysis is that mean ratio of this mixture for brain is estimated to be a ratio of $70 \%$ venous to $30 \%$ arterial blood by volume [11]. Whole body tissues are also estimated to contain the same mean ratio of $70 \%$ venous to $30 \%$ arterial blood by volume [24]. Therefore, to validate NIRS, oxygenation measurements of both venous and arterial blood need to be weighted from the venous output and arterial inputs of a target organ. For the brain, arterial blood supply is primarily from the carotid arteries and the primary venous drainage is by the internal jugular vein/jugular bulb. For somatic tissue, arterial blood supply is primarily from the descending aorta and the primary venous drainage is the vena cava leading to the right atrium. Because arterial blood oxygenation is similar in the larger blood vessels in the absence of congenital defects, blood was drawn from a catheter placed in the radial artery.

\subsection{Study protocol}

The goal of this study was to evaluate the performance of the FORE-SIGHT ELITE in healthy volunteers during a controlled hypoxia sequence at steady-state $\mathrm{ETCO}_{2}$ levels to measure cerebral and somatic $\mathrm{StO}_{2}$ with the adult Large sensors. Subjects were healthy adult volunteers who were compensated for their study participation. Written informed consent was obtained from each subject prior to the initiation of any pre-study examination. Subjects were enrolled in either the cerebral or somatic cohort as venous catheter placement could only be in one location. For cerebral, a catheter was placed in the right jugular bulb for blood sampling, with location verified by X-ray. For somatic, a catheter was placed for blood sampling in the superior vena cava outside of the right atrium.

For cerebral $\mathrm{StO}_{2}$ validation, a Large sensor was placed on the left or right forehead close to the hairline, with placement alternated by even or odd subject number. The monitor's values were compared to the calculated cerebral oxygen saturation (derived from co-oximeter measured arterial and jugular bulb venous oxygen saturations) during the sequential desaturation study.

For somatic $\mathrm{StO}_{2}$ validation, three Large sensors were placed on the flank, quadriceps, and calf muscles preferably at a high muscle density location. Sensor placements were alternated on the left or right side by even or odd subject number. The monitor's values were compared to the calculated somatic oxygen saturation (derived from co-oximeter measured arterial and central venous oxygen saturations) during the sequential desaturation study.

The level of oxygen within the blood was reduced in a controlled manner by altering the inspired oxygen concentration $\left(\mathrm{FiO}_{2}\right)$ to achieve arterial oxygen saturation plateaus between 100 and $70 \%$ as measured by a finger pulse oximeter on the finger. An attending anesthesiologist was present for each individual study. The anesthesiologist continuously monitored subject's safety and managed the conduct of the study protocol. The subject's tolerance of the study procedures was continually assessed and, if necessary, the study was prematurely terminated by subject request or clinical discretion.

First, the controlled hypoxia evaluation was conducted. The level of oxygen within the blood was reduced in a controlled manner by the RespirAct ${ }^{\circledR}$ (Thornhill Research, Toronto, Canada) sequential gas delivery system (consisting of gas tanks, gas blender, facemask and control laptop with continuously displayed $\mathrm{O}_{2}$ and $\mathrm{CO}_{2}$ ) which permitted independent control of the both the $\mathrm{ETO}_{2}$ and $\mathrm{ETCO}_{2}$ to reach target values. $\mathrm{ETCO}_{2}$ was regulated to a target of $40 \mathrm{mmHg}( \pm 2)$ to normalize cerebral vasoreactivity to $\mathrm{CO}_{2}$ among subjects, to minimize changes in the venous and arterial blood volumes in cerebral tissue. The measured 
$\mathrm{ETO}_{2}$ and $\mathrm{ETCO}_{2}$ were used to closely match the target arterial $\mathrm{O}_{2}$ and $\mathrm{CO}_{2}\left(\mathrm{PaO}_{2}\right.$ and $\left.\mathrm{PaCO}_{2}\right)$, respectively. The $\mathrm{PaO}_{2}$ in turn determined the resultant $\mathrm{SpO}_{2}$. One (1) room air and eight (8) $\mathrm{ETO}_{2}$ plateaus were targeted, with resulting eight $\mathrm{SpO}_{2}$ plateaus between 70-100\% (Fig. 1). At each plateau a set of paired arterial and jugular venous blood gas samples were drawn in heparinized syringes approximately 5 min after the $\mathrm{FiO}_{2}$ step, when the $\mathrm{SpO}_{2}$ and $\mathrm{StO}_{2}$ values stabilized. Blood samples were processed by a co-oximeter (ABL 90, Radiometer, Copenhagen, Denmark) to measure the arterial $\left(\mathrm{S}_{\mathrm{a}} \mathrm{O}_{2}\right)$ and jugular venous $\left(\mathrm{S}_{\mathrm{jv}} \mathrm{O}_{2}\right)$ oxygen saturations. Tissue oximetry measurements and blood samples were time-synchronized at each plateau. ECG, pulse, blood pressure, $\mathrm{SpO}_{2}, \mathrm{ETCO}_{2}$, and $\mathrm{ETO}_{2}$ were monitored throughout the study.

Institutional Review Boards (IRB) and Ethics Committees will only allow healthy volunteers to participate in low risk studies. The placement of the IJV bulb catheter represents a potential risk to healthy volunteers, though the precise risk of complications is difficult to quantify. Jugular bulb catheters have been used not only in healthy volunteers for oximeter validation studies but also for high altitude [57] and breath hold diving studies [58] without reported complications. In neuro-intensive care and neurosurgical patients several studies [59-63] have reported the safe use of jugular bulb catheters for clinical monitoring purposes. In the study by Coplin et al. [64], the authors reported a $40 \%$ incidence of thrombus at or near the site of line placement following line removal from 44 neuro-intensive care patients. Of particular note, the median duration of jugular line monitoring was 3 days and all the thrombi were considered subclinical with no patient experiencing symptoms. Therefore, we consider that the placement of IJV bulb catheters in healthy volunteers by experienced medical personnel using ultrasound guidance and for short periods of data collection (typically less than $4 \mathrm{~h}$ ) to be appropriate and to constitute a low risk to study participants. There are published studies conducted under similar conditions to those defined for this study that demonstrate that healthy subjects tolerate the mild hypoxia and jugular bulb catheterization well without adverse outcomes [1, 2, 9, 10, 12].

Standard clinical procedure should be followed when performing jugular bulb catheterization to minimize risks $[65,66]$. This study employs methods similar to the standard protocols recommended by the FDA and ISO Standards for testing pulse oximeters with mild hypoxia steps and blood drawn from arterial catheters (ISO 80601-2-61:2011) [67].

\subsection{Data analysis \& statistical considerations}

The monitor's forehead cerebral $\mathrm{StO}_{2}$ measurements were compared to the weighted co-oximetry reference $\left(\mathrm{REF} \mathrm{CX}_{\mathrm{B}}\right.$ ) based on the assumed $70: 30$ brain tissue venous:arterial (V:A) blood volume ratio [11] from the following equation [7]:

$\operatorname{REFCX} \mathrm{CX}_{\mathrm{B}}=\left(0.7 \times S_{j v} \mathrm{O}_{2}\right)+\left(0.3 \times S_{a} O_{2}\right)$
Fig. 1 Stepped Hypoxia Plateau Sequence Protocol with targeted pulse oximetry $\mathrm{SpO}_{2}$ values and estimated $\mathrm{ETO}_{2}$ values previously derived experimentally from $\mathrm{SpO}_{2}$. For the NIRS cerebral $\mathrm{StO}_{2}$ validation portion of the protocol, jugular venous and arterial blood samples are drawn for co-oximetry analysis when the cerebral $\mathrm{StO}_{2}$ value stabilizes for each step. Likewise for NIRS somatic $\mathrm{StO}_{2}$ validation portion of the protocol, central venous and arterial blood samples are drawn for co-oximetry analysis when the somatic $\mathrm{StO}_{2}$ values from flank, quadriceps, and calf muscle stabilize for each step

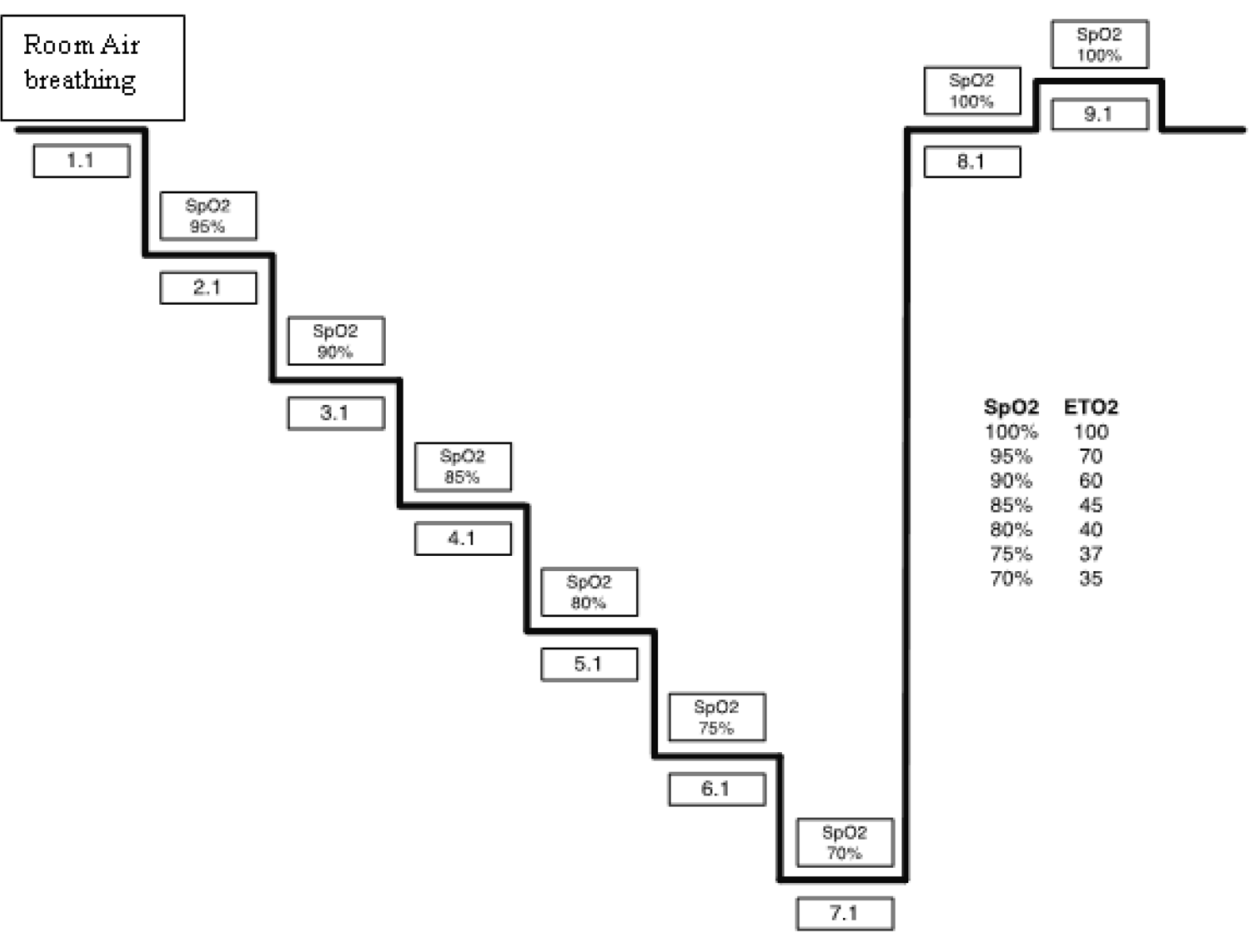


where $\mathrm{S}_{\mathrm{jv}} \mathrm{O}_{2}$ and $\mathrm{S}_{\mathrm{a}} \mathrm{O}_{2}$ are the functional oxygen saturations from the blood samples drawn simultaneously from the internal jugular venous (jugular bulb) and systemic arterial catheters, respectively, and measured using a co-oximeter.

The monitor's somatic $\mathrm{StO}_{2}$ readings were compared to the weighted co-oximetry reference $\left(\mathrm{REF} \mathrm{CX}_{\mathrm{S}}\right)$ based on the assumed 70:30 somatic tissue V:A blood volume ratio [24] from the following equation:

$$
\mathrm{REFCX}_{\mathrm{S}}=\left(0.7 \times \mathrm{S}_{c v} \mathrm{O}_{2}\right)+\left(0.3 \times \mathrm{S}_{a} \mathrm{O}_{2}\right)
$$

where $\mathrm{S}_{\mathrm{cv}} \mathrm{O}_{2}$ and $\mathrm{S}_{\mathrm{a}} \mathrm{O}_{2}$ are the functional oxygen saturations from the blood samples drawn simultaneously from the vena cava (near the right atrium), and systemic arterial catheters, respectively, and then measured using a co-oximeter.

We performed the Bland-Altman analysis [68] to evaluate the agreement between the measured $\mathrm{StO}_{2}$ and the REF CX, overall and within subgroups (e.g., light, moderate, and dark skin tones). Bias and precision (1 SD) were reported. Since the study design included repeated measurements within the same patient, a modified Bland-Altman analysis taking into account the repeated measures was performed using the MethComp package in R (http:// BendixCarstensen.com/MethComp). We categorized Caucasian (White) subjects as having light skin tone, Asian and Hispanic subjects as having moderate skin tone, and African American (Black) subjects as having dark skin tone. For accuracy determinations, multiple subject data points were not binned like the alternative method of Ikeda, et al. [10]. We used both the random coefficients model and the Deming regression to estimate the intercept and slope (with 95\% confidence intervals) of the measured $\mathrm{StO}_{2}$ against REF CX, following that of past FDA accepted $510 \mathrm{~K}$ clearances. The FDA favors the use of Deming regression [69], because it accounts for errors in observations on both the $\mathrm{x}$-axis (REF CX reference) and the $\mathrm{y}$ - axis (measured $\mathrm{StO}_{2}$ ). The advanced regression methods add value by demonstrating the robustness of the validation. Results between the Deming regression and the traditional linear regression allow visual comparison to demonstrate consistency and similarity of the two methods to compensate for any possible weaknesses of each method. Also presented is the concordance correlation coefficient (CCC) [70], which is similar to the Pearson's correlation coefficient but consists of a measure of precision multiplied by a measure of accuracy. Historically, successful cerebral oximeter FDA $510 \mathrm{~K}$ applications using a similar healthy adult hypoxia protocol have been based upon data from 17 to 23 subjects [71-73]. Power analysis shows that under the assumption that the true precision is 3\%, there is an $80 \%$ chance that an experiment with 24 subjects will reliably detect an observed precision of $3.8 \%$ or less.

\subsection{Dependent data considerations}

Because each subject had 9 data points each, the data are not independent. Therefore, a more complex analysis is detailed as follows. Deming regression assumes the reference (REF CX) is subject to measurement error. A Deming regression line will be fitted for each subject resulting in 25 regression lines with slope and intercept for the 25 subjects. Initial Q statistic analysis showed that the estimated standard errors for the regression coefficients are not homogeneous as some subjects have larger variation than others due to subject effect (not pure instrumental random error). This factor is taken into account when the estimates of intercepts and slopes are "pooled" together as part of a twostep process. Specifically, in Step 1, the Deming regression coefficients are determined for each subject, and then their standard errors are determined using the Jackknife method $[74,75]$. In Step 2, the "Meta Analysis" technique is used to pool these estimates together to generate a weighted average intercept and a weighted average slope [76]. The pooled analysis considers that subjects are random samples from a general population.

Random Coefficients Model is a traditional method of linear regression and an alternate technique for analysis of subject dependent data. It assumes that each subject has his/her trajectory or inherent trend of the repeated measurements. The inherent trajectories are "high" or "low" with different steepness across subjects, suggesting that the subject-specific intercept and slope [77]. The concordance correlation coefficient (CCC) was used to demonstrate agreement for continuous data in this model. It can be used in the context of multiple repeated measurements per subject, and thus is valid for this study. [78].

\subsection{Bootstrap model validation}

Bootstrapping is a statistical method for estimating the sampling distribution of an estimator by sampling with replacement from the original sample, with the purpose of deriving robust estimates of standard errors and confidence intervals of a population parameter such as regression correlation coefficient and confidence intervals. The regression methods (Deming regression and Random Coefficients Model) and CCC calculation were validated by two bootstrapping methods, Bootstrap I and Bootstrap II. The Bootstrap 95\% confidence interval (CI) method was computed two different ways: "Normal"-normal approximation; and "Bias Corr"-bias-corrected percentile method. For Bootstrap $I$, individual subject data was bootstrapped without doing any moving block bootstrapping for repeated measurements within subjects. Sherman and le Cessie [79] present an 'all block bootstrap' by resampling blocks of individual subjects. They argued that, by bootstrapping these 
blocks, the correlation structure within each block could be maintained and the bootstrap intervals could be produced in an automatic way so that the correlation structure can be left unspecified. For Bootstrap II, we performed a second bootstrap method which does double bootstrapping for panel data (i.e., bootstrap for both subject and time series data) based on Davison and Hinkley [80]. For this method, we bootstrapped individual subjects first and then bootstrapped observations within individual subjects using the moving block method with block size 3 and overlap size 2. This is determined from the dataset, where there were 9 observations per subject where the desire block size is $\mathrm{n}^{* *(1 / 3)}$ which is $9^{* *(1 / 3)} \sim 2$ or 3 .

\subsection{Uncertainty analysis}

Because it is likely that the assumed 70:30 brain tissue V:A volume ratio varies between subjects and with physiological conditions [81], weighted cerebral co-oximetry reference $\left(\mathrm{REF} \mathrm{CX} \mathrm{CX}_{\mathrm{B}}\right)$ based on the $\mathrm{StO}_{2}$ values were also compared to other brain tissue $\mathrm{V}$ :A volume ratios from $60: 40$ to $80: 20$ to quantify potential errors due to varying V:A volume ratios.

\section{Results}

\subsection{Cerebral validation study}

With informed consent, 25 subjects successfully completed the cerebral validation study with the following demographics: 15 White, 5 Black, 4 Asian, and 1 Hispanic subject, with 12 Males and 13 Females. Weight range was 44.6-108.9 kg; and age range was: $19.4-41.7$ years.

Nine data points were obtained per subject from each $\mathrm{FiO}_{2}$ step along with $\mathrm{REF} \mathrm{CX}_{\mathrm{B}}$ for a total of 225 paired data points.

The bias and precision (1 SD) of the monitor's cerebral $\mathrm{StO}_{2}$ measurement vs $\mathrm{REF} \mathrm{CX}_{\mathrm{B}}$ for the three skin tone groups (light, moderate, and dark skin tones) are shown in
Table 1. Figure 2 shows a scatterplot of the individual data points for the three skin tone types.

The monitor's $\mathrm{StO}_{2}$ measurements from the right forehead sensor demonstrated an overall bias \pm precision (1 SD) of $0.03 \pm 3.02 \%$ (12 subjects), while the left forehead sensor demonstrated an overall bias \pm precision (1 SD) of $-0.30 \pm 3.13 \%$ (13 subjects). Cerebral $\mathrm{StO}_{2}$ accuracy of both cerebral hemispheres was similar, even though jugular bulb catheterization was always on the right side.

The cerebral $\mathrm{StO}_{2}$ versus $\mathrm{REF} \mathrm{CX}_{\mathrm{B}}$ Deming regression was $y=0.966 x+2.447$ and Random Coefficients model was $y=0.977 x+1.728$ demonstrating the similarity of the results using subject dependent data regression techniques. The Concordance Correlation Coefficient (CCC) was 0.948. Using the rigorous Bootstrap techniques (Bootstrap I and Bootstrap II) for model validation, the Deming regression, Random Coefficients model, and CCC parameters were very similar to the observed values. The confidence intervals increase slightly when using the Bootstrap methods (Table 2).

The cerebral $\mathrm{StO}_{2}$ values were compared to various weighted cerebral co-oximetry reference $\left(\mathrm{REF} \mathrm{CX} \mathrm{CX}_{\mathrm{B}}\right)$ in the uncertainty analysis. For brain tissue V:A volume ratios of $60: 40,65: 35,70: 30,75: 25$, and 80:20, the bias and precision ( $1 \mathrm{SD}$ ) of $\mathrm{StO}_{2}$ was $2.87 \pm 2.82 \%, 1.37 \pm 2.92 \%$, $-0.14 \pm 3.05 \%,-1.65 \pm 3.20 \%$, and $-3.16 \pm 3.37 \%$, respectively. The bias of $\mathrm{StO}_{2}$ versus $\mathrm{REF} \mathrm{CX}_{\mathrm{B}}$ changes about $0.30 \%$ per one point shift in the $\mathrm{V}$ :A volume ratio resulting in bias changes of $\pm 3.0 \%$ for ratios of $60: 40$ or $80: 20$ the compared to the selected $\mathrm{V}: \mathrm{A}$ ratio of $70: 30$. The mean $\mathrm{SaO}_{2}-\mathrm{SjvO}_{2}$ difference for all values was $30.15 \pm 6.17$ (1 $\mathrm{SD})$.

\subsection{Somatic validation study}

With informed consent, 24 subjects successfully completed the somatic validation study with the following demographics: 8 White, 14 Black, and 2 Asian, with 15 Male and 9 Female subjects. Weight range was $51.0-96.5 \mathrm{~kg}$; and age range was: 19-40 years. Nine somatic $\mathrm{StO}_{2}$ measurements from the flank, quad, and calf ( 27 measurements total) were
Table 1 Accuracy performance indicated by (Bias \pm precision, $1 \mathrm{SD})$ of the monitor's cerebral $\mathrm{StO}_{2}$ measurements versus REF $\mathrm{CX}_{\mathrm{B}}$ for the three skin tone groups (light, moderate, and dark skin tones)

\begin{tabular}{llllr}
\hline Skin tone & $\begin{array}{l}\text { Subject } \\
(\mathrm{N})\end{array}$ & $\begin{array}{l}\text { Data points } \\
(\mathrm{N})\end{array}$ & Deming regression equation & \multicolumn{1}{c}{$\begin{array}{l}\text { Cerebral StO }_{2} \\
(\mathrm{Bias} \pm 1 \mathrm{SD})^{*}\end{array}$} \\
\hline All & 25 & 225 & $\mathrm{StO}_{2}=2.45+0.97 \mathrm{REF}$ & $-0.14 \pm 3.07(3.05)$ \\
Light & 15 & 135 & $\mathrm{StO}_{2}=0.30+0.99 \mathrm{REF}$ & $-0.09 \pm 3.27(3.23)$ \\
Moderate & 5 & 45 & $\mathrm{StO}_{2}=2.54+0.95 \mathrm{REF}$ & $0.52 \pm 2.59(2.53)$ \\
Dark & 5 & 45 & $\mathrm{StO}_{2}=6.96+0.92 \mathrm{REF}$ & $-0.96 \pm 2.90(2.86)$ \\
\hline
\end{tabular}

Comparison of Light versus Moderate tone and Light versus Dark tone were not statistically significant ( $\mathrm{P}>0.05$, $\mathrm{t}$-test for means)

*Precision reported using Modified Bland-Altman for dependent data, with the more commonly reported standard Bland-Altman precision shown in parentheses 


\section{Cerebral StO2 vs REF CXB}

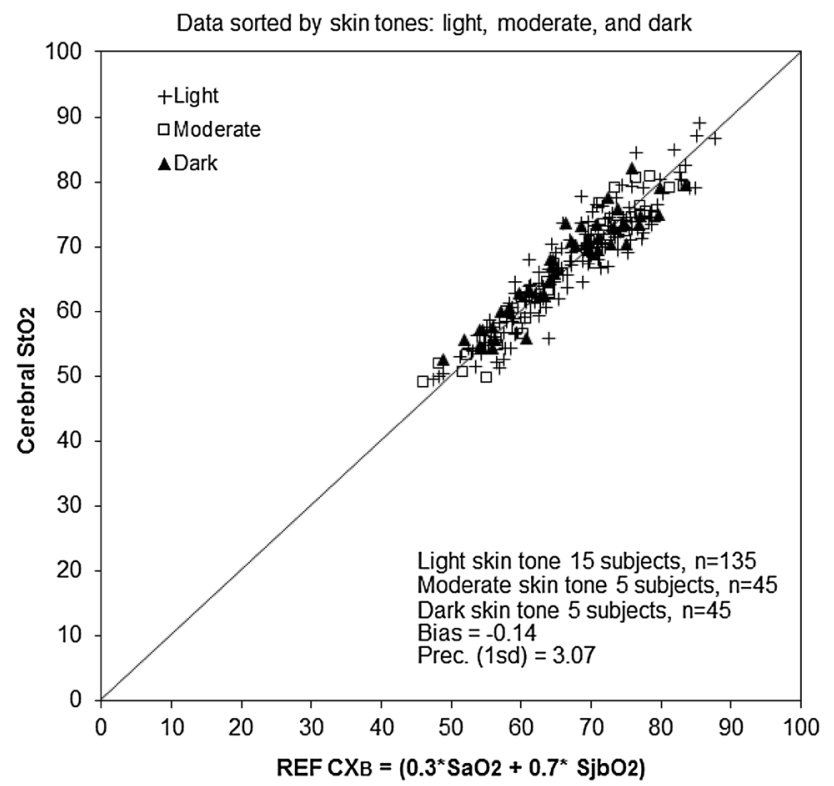

Fig. 2 Scatter plot comparison of cerebral $\mathrm{StO}_{2}$ measurements to cooximetry reference $\left(\mathrm{REF} \mathrm{CX} \mathrm{C}_{\mathrm{B}}\right)$ with data points marked by skin tone (dark, moderate, and light)

obtained per subject from the three sensors along with REF $\mathrm{CX}_{\mathrm{S}}$.

Figure 3 shows a scatterplot of $\mathrm{StO}_{2}$ versus $\mathrm{REF} \mathrm{CX}_{\mathrm{S}}$ for flank, quad, and calf overlaid. The bias and precision (1 $\mathrm{SD})$ of separated flank, quad, and calf somatic $\mathrm{StO}_{2}$ versus REF CX $\mathrm{S}_{\mathrm{S}}$ are shown in Table 3. Figure 4 shows a scatterplot of $\mathrm{StO}_{2}$ versus REF CX for averaged flank, quad, and calf $\mathrm{StO}_{2}$ values at each blood draw time for the three skin tone groups (light, moderate, and dark skin tones). The bias and precision (1 SD) of $\mathrm{StO}_{2}$ average of flank, quad, and calf values for the three skin tone groups versus REF $\mathrm{CX}_{\mathrm{S}}$ are shown in Table 3.

The averaged (flank, quad, \& calf) somatic $\mathrm{StO}_{2}$ versus $\mathrm{REF} \mathrm{CX}_{\mathrm{S}}$ Deming regression was $\mathrm{y}=0.867 \mathrm{x}+9.514$ and Random Coefficients model was $y=0.846 x+10.929$ demonstrating the similarity of the results using subject dependent data regression techniques. The differences between the flank, quad, and calf in terms of individual Deming regression equations (Table 3 ) where quad and calf slopes are lower than flank, as well as bias \& precision may have an influence on the overall regression slope and intercept when the data points are averaged. The Concordance Correlation Coefficient (CCC) was 0.821. Using the rigorous Bootstrap techniques (Bootstrap I and Bootstrap II) for model validation, the Deming regression, Random Coefficients model, and CCC parameters were very similar to the observed values. The confidence intervals increase slightly when using the Bootstrap methods. The averaged somatic site $\mathrm{StO}_{2}$ compared to the global REF $\mathrm{CX}_{\mathrm{S}}$ accuracy was better than the individual somatic site $\mathrm{StO}_{2}$ measurements, and accuracy decreased as the somatic measurement body location was made farther away from the central venous REF $\mathrm{CX}_{\mathrm{S}}$ blood draw location (Table 4). Also cerebral $\mathrm{StO}_{2}$ accuracy vs REF CX $\mathrm{B}$ was better than somatic $\mathrm{StO}_{2}$ vs REF CX .

\section{Discussion}

The validation methodology of tissue oximeters to invasive blood reference values assumes a fixed venous to arterial (V:A) blood volume ratio that can be applied to all subjects. The V:A blood volume ratio likely varies, with different analyses suggesting cerebral V:A blood volume ratios ranging from $54: 46$ to $84: 16$ [7, 82]. Because 70:30 is near the midpoint of the estimated V:A range [7] and imaging techniques also suggest the mean cerebral V:A blood volume ratio is approximately 70:30 among different subjects in steady state healthy conditions [11], we believe that an V:A ratio of 70:30 is a reasonable assumption for the brain. Our data indicates that if the actual V:A ratio varied 60:40-80:20 between subjects, the bias of $\mathrm{StO}_{2}$ versus REF $\mathrm{CX}_{\mathrm{B}}$ would change $\pm 3.0 \%$ compared to the selected V:A ratio of 70:30. The high precision of the FORE-SIGHT ELITE (3.07\% $1 \mathrm{SD}$ ) for cerebral $\mathrm{StO}_{2}$ against the fixed 70:30 reference weighting across the $\mathrm{StO}_{2} 50-90 \%$ saturation range therefore suggests that for healthy subjects under controlled $\mathrm{PaCO}_{2}$ conditions, the inter- and intra-subject subject variability of V:A ratio is likely less than $\pm 10 \%$. As an indirect comparison, pulse oximetry precision for adults derived from a controlled hypoxia study is $\sim 2 \%$ (1 SD) when compared to arterial blood oxygen saturation [83]. It is unlikely that in-vivo validated NIRS tissue oximetry systems will reach pulse oximeter precision, in part because NIRS tissue oximeters need both arterial and venous blood oxygen saturation co-oximeter measurements, which adds more variability to the REF CX reference measurement, and also because NIRS tissue oximetry interrogates deeper into tissues to make a $\mathrm{StO}_{2}$ measurement. Note that an NIRS monitor cannot measure the actual V:A blood volume ratio in tissue and does not distinguish venous and arterial contributions, a common point of confusion of NIRS monitors. The V:A ratio is only used to derive a reference from blood samples during validation of the NIRS monitor.

An interpretation of this data is that the inter-subject variability of cerebral vasoreactivity during controlled $\mathrm{PaCO}_{2}$ conditions is likely low within healthy adult subjects. The mean V:A ratio will then be likely less variable compared to other patient populations with morbidities or during uncontrolled $\mathrm{PaCO}_{2}$ states. Therefore, validation with healthy adult subjects with controlled $\mathrm{PaCO}_{2}$ may serve as 
Table 2 Comparison of cerebral $\mathrm{StO}_{2}$ measurements to co-oximetry reference $\left(\mathrm{REF} \mathrm{CX}_{\mathrm{B}}\right)$ : Deming and Random Coefficients Model Regression, CCC, and Bootstrap I and Bootstrap II Validation

\begin{tabular}{|c|c|c|c|c|}
\hline Method & $\begin{array}{l}\text { Original or bootstrap (bias-cor- } \\
\text { rected) statistic }\end{array}$ & Standard error & $\begin{array}{l}\text { Lower } 95 \% \text { confidence } \\
\text { limit }\end{array}$ & $\begin{array}{l}\text { Upper } 95 \% \\
\text { confidence } \\
\text { limit }\end{array}$ \\
\hline \multicolumn{5}{|c|}{ Deming regression } \\
\hline \multicolumn{5}{|l|}{ Intercept } \\
\hline Observed & 2.447 & 1.849 & -1.176 & 6.071 \\
\hline Bootstrap I & 2.511 & 2.626 & -2.093 & 7.937 \\
\hline Bootstrap II & 3.029 & 2.967 & -2.921 & 8.368 \\
\hline \multicolumn{5}{|l|}{ Slope } \\
\hline Observed & 0.966 & 0.0287 & 0.909 & 1.022 \\
\hline Bootstrap I & 0.964 & 0.040 & 0.882 & 1.041 \\
\hline Bootstrap II & 0.958 & 0.046 & 0.878 & 1.054 \\
\hline \multicolumn{5}{|c|}{ Random coefficients model } \\
\hline \multicolumn{5}{|l|}{ Intercept } \\
\hline Observed & 1.728 & 2.450 & -3.328 & 6.784 \\
\hline Bootstrap I & 1.800 & 2.464 & -2.766 & 6.654 \\
\hline Bootstrap II & 1.783 & 2.603 & -3.773 & 6.763 \\
\hline \multicolumn{5}{|l|}{ Slope } \\
\hline Observed & 0.977 & 0.0390 & 0.897 & 1.058 \\
\hline Bootstrap I & 0.976 & 0.039 & 0.900 & 1.055 \\
\hline Bootstrap II & 0.976 & 0.041 & 0.898 & 1.062 \\
\hline \multicolumn{5}{|c|}{$\begin{array}{l}\text { Concordance correlation coefficient } \\
(\mathrm{CCC})\end{array}$} \\
\hline Observed & 0.948 & 0.015 & 0.877 & 0.960 \\
\hline Bootstrap I & 0.954 & 0.023 & 0.891 & 0.975 \\
\hline Bootstrap II & 0.916 & 0.008 & 0.929 & 0.929 \\
\hline
\end{tabular}

Bootstrap I: Single Bootstrapping for dependent data-bootstrap individuals only and then sample entire block for each selected subject

Bootstrap II: Double Bootstrapping for dependent data-bootstrap individuals and then bootstrap observations within individuals using the moving block method with block size 3 and overlap size 2

Bootstrap CI method: bias-corrected percentile method

Bootstrap sample $=500$

a control. Measured precision and regression parameters would then be indicators on how the tissue oximeter performs under near-ideal conditions. A tissue oximeter that shows more variability when compared to a reference under near-ideal conditions, will likely demonstrate more variability when used as a clinical monitor. A controlled tissue oximetry validation cannot be performed for pediatric and neonatal subjects for ethical reasons and so non-healthy pediatric subjects undergoing cath-lab procedures are commonly used [13, 23, 84, 85]. As a result, precision and regression parameters from pediatric tissue oximetry validation exhibit more variability compared to a control study $[13,85]$. Because tissue oximetry general sensor and algorithm designs are usually similar for a particular model tissue oximeter among different subject populations, the adult validation may indirectly serve as a reference for pediatric tissue oximetry performance as well.
It is understood that the cerebral venous to arterial blood volume ratio varies physiologically in the tissue vasculature that is interrogated by a NIRS sensor [7, 86-88] as $\mathrm{PaCO}_{2}$ normally varies among human and other mammalian subjects. Since $\mathrm{CO}_{2}$ is a potent vasodilator to the cerebral vasculature, $\mathrm{PaCO}_{2}$ levels in blood can shift the $\mathrm{V}$ :A ratio where high $\mathrm{PaCO}_{2}$ levels (hypercapnia) would drive arterial blood volume ratio to be greater than $30 \%$ while low $\mathrm{PaCO}_{2}$ levels (hypocapnia) would drive arterial blood volume ratio to be less than $30 \%$ [89, 90]. Because hypocapnia results in vasoconstriction of cerebral arterial blood vessels, resulting in reduced flow, cerebral tissue ischemia can result [91-95]. In addition to the effects of lower perfusion, a NIRS sensor would also interrogate less arterial blood volume relative to venous blood volume in the tissue. This compound effect will result in a decrease of $\mathrm{StO}_{2}$, which would alert the clinician and warrant a check in $\mathrm{PaCO}_{2}$ levels 
Somatic StO2 (Flank, Quad, and Calf)

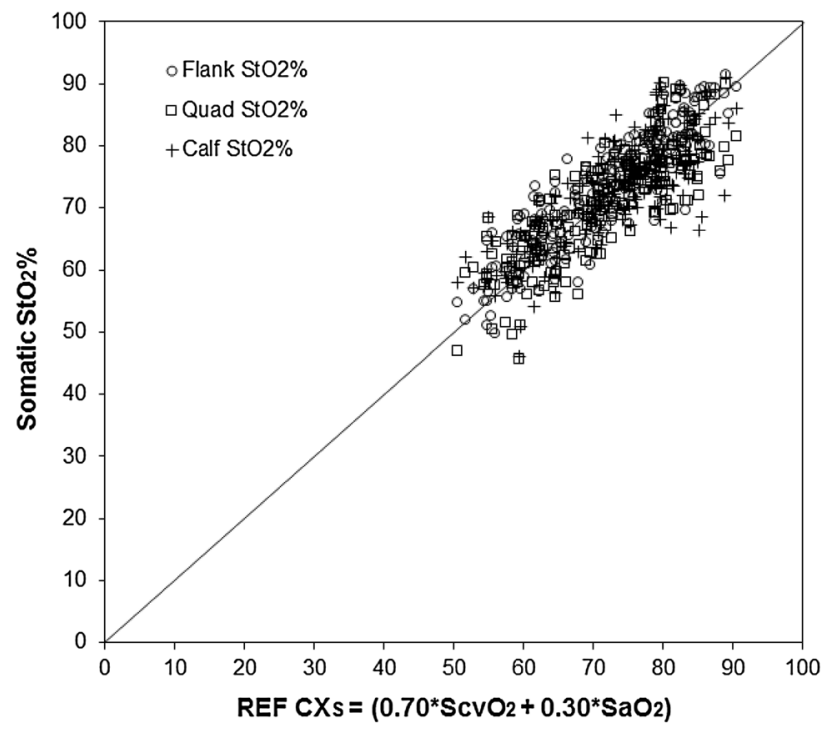

Fig. 3 Scatter plot comparison of individual somatic $\mathrm{StO}_{2}$ measurements (flank, quad, and calf) versus Co-Oximetry Reference (REF $\left.\mathrm{CX}_{\mathrm{S}}\right)$

[96-98]. Reduced minute ventilation to increase $\mathrm{CO}_{2}$ levels is often used as an intervention to increase cerebral blood flow and resultant perfusion [99-103]. In this case, a NIRS sensor would detect an increase of arterial blood volume relative to venous blood volume as well as an increase in flow resulting in an increase of $\mathrm{StO}_{2}$, the desired effect. Therefore, we believe that a cerebral tissue oximeter validated using a controlled fixed V:A blood volume ratio $\mathrm{REF} \mathrm{CX}_{\mathrm{B}}$ reliably provides clinicians real time information of the effect of both adverse and beneficial changes in cerebral vasoreactivity and V:A blood volume ratio shifts.

For the somatic co-oximeter reference REF $\mathrm{CX}_{\mathrm{S}}$, the mean V:A non-cerebral tissue blood volume ratio was also assumed to be $70: 30$ among different subjects in steady state healthy conditions. This assumption was based on the findings of Pang et al. [24] where the venous system of the whole body contains $70 \%$ of total blood volume. However, somatic tissue blood volume V:A ratios can vary greatly under normal and abnormal physiological conditions. For example, muscle exercise may dynamically change V:A ratio between contraction and relaxation. Body position, such as standing upright, may result in pooling venous blood volume in the lower extremities compared to the supine position. Therefore, for somatic validation, the subjects were in the supine position and relaxed, with negligible muscle activation resulting in resting state metabolism for the somatic sensor measurement sites. This controlled resting state appeared to effectively limit the variation in $\mathrm{V}: \mathrm{A}$ blood volume ratio as evidenced by somatic $\mathrm{StO}_{2}$ accuracy measurements within $6 \%$ (1 SD) compared to a fixed 70:30 blood volume ratio REF $\mathrm{CX}_{\mathrm{S}}$.

The results showed that the somatic $\mathrm{StO}_{2}$ measurement precision and individual Deming regression slope decreased as the body location moved farther away from

Table 3 Accuracy performance indicated by (Bias \pm precision, $1 \mathrm{SD}$ ) of Somatic $\mathrm{StO}_{2}$ versus $\mathrm{REF} \mathrm{CX}_{\mathrm{S}}$ for the individual three body locations monitored (Flank, Quad, and Calf)

\begin{tabular}{|c|c|c|c|c|c|}
\hline Skin tone & Body location & $\begin{array}{l}\text { Subject } \\
(\mathrm{N})\end{array}$ & $\begin{array}{l}\text { Data points } \\
(\mathrm{N})\end{array}$ & Deming regression equation & $\begin{array}{l}\text { Somatic } \mathrm{StO}_{2} \\
(\mathrm{Bias} \pm 1 \mathrm{SD})^{*}\end{array}$ \\
\hline \multirow[t]{4}{*}{ All } & Flank & 24 & 216 & $\mathrm{StO}_{2}=4.78+0.95 \mathrm{REF}$ & $-1.12 \pm 4.45(4.42)$ \\
\hline & Quadriceps & 24 & 216 & $\mathrm{StO}_{2}=7.54+0.88 \mathrm{REF}$ & $1.11 \pm 5.41(5.37)$ \\
\hline & Calf & 23 & 201 & $\mathrm{StO}_{2}=15.13+0.79 \mathrm{REF}$ & $0.03 \pm 5.91(5.88)$ \\
\hline & Average of Flank/Quad/Calf & 24 & 216 & $\mathrm{StO}_{2}=9.51+0.87 \mathrm{REF}$ & $0.04 \pm 4.22(4.20)$ \\
\hline \multirow[t]{4}{*}{ Light } & Flank & 8 & 72 & $\mathrm{StO}_{2}=1.17+1.00 \mathrm{REF}$ & $-0.66 \pm 4.41$ \\
\hline & Quadriceps & 8 & 72 & $\mathrm{StO}_{2}=6.18+0.90 \mathrm{REF}$ & $1.58 \pm 5.19$ \\
\hline & Calf & 8 & 72 & $\mathrm{StO}_{2}=20.84+0.71 \mathrm{REF}$ & $0.90 \pm 4.63$ \\
\hline & Average of Flank/Quad/Calf & 8 & 72 & $\mathrm{StO}_{2}=9.26+0.87 \mathrm{REF}$ & $0.62 \pm 3.77$ \\
\hline \multirow[t]{4}{*}{ Moderate } & Flank & 2 & 18 & $\mathrm{StO}_{2}=11.77+1.19 \mathrm{REF}$ & $-2.06 \pm 3.61$ \\
\hline & Quadriceps & 2 & 18 & $\mathrm{StO}_{2}=-9.39+1.11 \mathrm{REF}$ & $1.11 \pm 5.12$ \\
\hline & Calf & 2 & 18 & $\mathrm{StO}_{2}=-3.10+1.07 \mathrm{REF}$ & $-2.32 \pm 4.31$ \\
\hline & Average of Flank/Quad/Calf & 2 & 18 & $\mathrm{StO}_{2}=-7.21+1.11 \mathrm{REF}$ & $-1.09 \pm 3.95$ \\
\hline \multirow[t]{4}{*}{ Dark } & Flank & 14 & 126 & $\mathrm{StO}_{2}=8.96+0.89 \mathrm{REF}$ & $-1.24 \pm 4.64$ \\
\hline & Quadriceps & 14 & 126 & $\mathrm{StO}_{2}=10.43+0.84 \mathrm{REF}$ & $-0.84 \pm 5.69$ \\
\hline & Calf & 13 & 117 & $\mathrm{StO}_{2}=16.25+0.77 \mathrm{REF}$ & $0.14 \pm 6.74$ \\
\hline & Average of Flank/Quad/Calf & 14 & 126 & $\mathrm{StO}_{2}=11.59+0.84 \mathrm{REF}$ & $-0.13 \pm 4.54$ \\
\hline
\end{tabular}

*Precision reported using Modified Bland-Altman for dependent data, with the more commonly reported standard Bland-Altman precision shown in parentheses for the All Skin Tone group 
Somatic StO2 (Average of Flank, Quad, and Calf) vs REF CXs Data sorted by skin tones: light, moderate, and dark

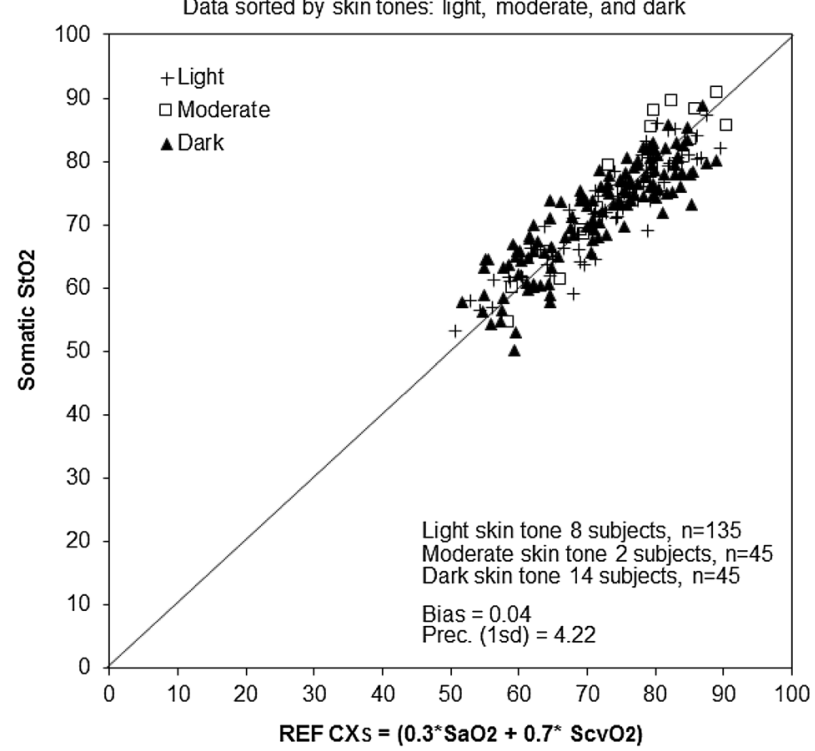

Fig. 4 Scatter plot comparison of the average of flank, quad, and calf $\mathrm{StO}_{2}$ measurements to the global Co-Oximetry Reference $\left(\mathrm{REF} \mathrm{CX} \mathrm{X}_{\mathrm{S}}\right.$ ), with data points marked by skin tone (dark, moderate, and light)

the heart compared to REF CX $\mathrm{S}_{\mathrm{S}}$. The Flank $\mathrm{StO}_{2}$ measurements showed the highest precision (4.45\%), followed by Quad $\mathrm{StO}_{2}$ measurements (5.41\%), then Calf $\mathrm{StO}_{2}$ measurements $(5.91 \%)$. Because the blood in the vena cava represent the global venous blood return of the body, multiple somatic $\mathrm{StO}_{2}$ measurements are averaged to better reflect the global $\mathrm{SvcO}_{2}$ co-oximetry measurement as part of REF $\mathrm{CX}_{\mathrm{S}}$, with a precision of $4.22 \%$ compared to the next best $4.45 \%$ of the Flank $\mathrm{StO}_{2}$ measurements alone. Due to heterogeneity in tissue oxygenation demand and metabolism, it is likely that somatic $\mathrm{StO}_{2}$ would have some variability at different body locations. An alternative validation method for limb muscle $\mathrm{StO}_{2}$ is to use blood from the venous return of the limb that is close to the muscle of interest [104] as opposed to the global vena cava venous return done in this study. Somatic $\mathrm{StO}_{2}$ measurements are best made on the larger muscles of the body, where NIRS light can diffuse and scatter unimpeded by the tissue geometry. Bony areas of the body such as ankles, wrists, and parts of the hands and feet, may alter the NIRS photon path to the sensor detectors, resulting in unreliable $\mathrm{StO}_{2}$ measurements, particularly with larger light source to detector configured sensors.

When validating tissue oximetry data to an internal blood reference, two different data analysis methods accepted by the U.S. FDA can be chosen. The first method involves splitting the subjects to two groups, calibration set and test set [12]. The second method involves pooling all subjects to a best fit model used to set algorithm parameters and then doing model validation using statistical techniques such as bootstrapping, which was done here. To determine which validation method to use, the following considerations need to be examined. For clinical validity and generalizability, the enrolled subject group should reflect those of the general population in terms of demographics such as weight, gender, and skin pigmentation. In a recent FDA guidance for pulse oximetry, the FDA recommends use of a minimum of 200 paired data points from at least 10 subjects where at least 2 subjects or $15 \%$ of subjects are darkly pigmented, whichever is larger [83]. Besides skin pigmentation, inter-subject variability of deeper tissue background optical properties can have an impact on tissue oximeter accuracy when compared to a blood reference. Such intersubject differences have been observed to result in physiologically anomalous readings or variable agreement to invasive blood references [12]. Deep tissue optical characteristics may include the optical effects of tissue, muscle, and bone density, heterogeneous tissue pigmentation, hair follicles, and scarring from prior injuries, contusions, concussions, or facial surgeries. Furthermore, anatomical variations influence the distribution and characteristics of the various tissue contributions. Since the background deep tissue optical characteristics cannot be determined by visually examining subjects and are independent of race, an effective sample size needs to have a high probability to include a wide range of subjects with different deep tissue optical characteristics.

Two follow-up first generation FORE-SIGHT studies with comparison to the invasive reference $\mathrm{REF} \mathrm{CX}_{\mathrm{B}}[105$, 106] showed consistency in precision following validation using the modeling and statistical validation method with 17 subjects [71]. The validation of another tissue oximeter using the calibration and test method splitting 23 subjects in two groups (11 calibration subjects and 12 test subjects) [12] gave an unexpected result where the test accuracy measurement was better than the calibration value, which may indicate that the test group subjects had less background tissue optical heterogeneity than the calibration group. For this reason, the approach described herein using the full data set for the best fit modeling and advanced statistical validation techniques was chosen for the FORESIGHT ELITE. By using a larger data set and accounting for sampling variability, this method may be more reliable in predicting clinical monitor performance over a wider range of subjects with different background optical characteristics. For validations done using the split subject datasets to two groups (calibration set and test set) to match the effective sample size that includes a wide range of subjects with different deep tissue optical characteristics, the overall effective subject sample size would need to be doubled.

When considering accuracy of NIRS tissue oximeters to other oximetry systems, the semi-invasive optical based 
Table 4 Comparison of average of flank, quad, and calf $\mathrm{StO}_{2}$ values to the global co-oximetry Reference (REF CX $\mathrm{S}_{\mathrm{S}}$ : Deming and random coefficients model regression, CCC, and Bootstrap I and Bootstrap II Validation

\begin{tabular}{|c|c|c|c|c|}
\hline Method & $\begin{array}{l}\text { Original or bootstrap (bias-cor- } \\
\text { rected) statistic }\end{array}$ & Standard error & $\begin{array}{l}\text { Lower } 95 \% \text { confidence } \\
\text { limit }\end{array}$ & $\begin{array}{l}\text { Upper 95\% } \\
\text { confidence } \\
\text { limit }\end{array}$ \\
\hline \multicolumn{5}{|c|}{ Deming regression } \\
\hline \multicolumn{5}{|l|}{ Intercept } \\
\hline Observed & 9.514 & 3.209 & 3.224 & 15.803 \\
\hline Bootstrap I & 9.453 & 3.455 & 2.388 & 15.722 \\
\hline Bootstrap II & 9.865 & 4.255 & 1.387 & 18.243 \\
\hline \multicolumn{5}{|l|}{ Slope } \\
\hline Observed & 0.867 & 0.043 & 0.783 & 0.952 \\
\hline Bootstrap I & 0.868 & 0.046 & 0.784 & 0.958 \\
\hline Bootstrap II & 0.863 & 0.057 & 0.748 & 0.976 \\
\hline \multicolumn{5}{|c|}{ Random coefficients model } \\
\hline \multicolumn{5}{|l|}{ Intercept } \\
\hline Observed & 10.929 & 3.405 & 3.885 & 17.974 \\
\hline Bootstrap I & 10.929 & 3.280 & 4.428 & 17.522 \\
\hline Bootstrap II & 10.724 & 3.835 & 3.542 & 18.310 \\
\hline \multicolumn{5}{|l|}{ Slope } \\
\hline Observed & 0.846 & 0.046 & 0.751 & 0.940 \\
\hline Bootstrap I & 0.845 & 0.044 & 0.760 & 0.936 \\
\hline Bootstrap II & 0.847 & 0.052 & 0.746 & 0.949 \\
\hline \multicolumn{5}{|c|}{$\begin{array}{l}\text { Concordance Correlation Coefficient } \\
\text { (CCC) }\end{array}$} \\
\hline Observed & 0.821 & 0.047 & 0.706 & 0.894 \\
\hline Bootstrap I & 0.840 & 0.067 & 0.677 & 0.917 \\
\hline Bootstrap II & 0.680 & 0.014 & 0.880 & 0.880 \\
\hline
\end{tabular}

Bootstrap I: Single Bootstrapping for dependent data-bootstrap individuals only and then sample entire block for each selected subject

Bootstrap II: Double Bootstrapping for dependent data—bootstrap individuals and then bootstrap observations within individuals using the moving block method with block size 3 and overlap size 2

Bootstrap CI method: bias-corrected percentile method

Bootstrap sample $=500$

$\mathrm{SvO}_{2}$ catheters may be the best for comparison. These catheters measure $\mathrm{SvO}_{2}$ in venous blood vessels around the heart (central venous) and internal jugular vein/jugular bulb, part of the brain venous drainage system. $\mathrm{SvO}_{2}$ catheters measure $\mathrm{SvO}_{2}$ directly with an optical interface to blood where light does not pass through tissues first like tissue oximetry. For three $\mathrm{SvO}_{2}$ catheter oximeter systems, in-vivo comparison with co-oximetry of blood samples demonstrated a precision of 4.3-7.1\% (1 SD) [107]. For the Edward Lifesciences (Irvine, CA) Vigileo ${ }^{\mathrm{TM}} \mathrm{SvO}_{2}$ catheter system, the in-vivo comparison with co-oximetry of blood samples demonstrated a precision of $4.1 \%$ (1 SD) $[108,109]$. The precision of FORE-SIGHT ELITE $\mathrm{StO}_{2}$ for cerebral (3.07\% $1 \mathrm{SD})$ and somatic $(4.22 \% 1 \mathrm{SD})$ are very comparable to optical $\mathrm{SvO}_{2}$ catheter oximetry systems.

An alternative method in validating NIRS tissue oximeters under development involves in-vitro tests on a liquid optical phantom [110-114]. The liquid phantom contains a predetermined solution of saline, human blood hemoglobin, Intralipid $^{\circledR}$, sodium bicarbonate, glucose, and baker's yeast to desaturate the hemoglobin $[110,111]$. An issue that needs to be resolved is that different NIRS devices measure different $\mathrm{StO}_{2}$ values from sensors placed on the phantom and in-vivo validated NIRS monitors produce different values than those independently measured on the blood inside the phantom [110,111]. This is in part due to the different algorithms of the monitors, the sensor optical configuration, how the monitors compensate for skin pigmentation and background optical properties other than hemoglobin, and the validation methodology of the monitor. Phantoms generally absorb and scatter light differently compared to that of tissue oximeter sensors placed on human subjects as evidenced by the attenuation of light from each sensor's light source wavelengths (personal observation). If the optical properties of phantoms and biological tissue are not well matched, a tissue oximeter $\mathrm{StO}_{2}$ algorithm may behave 
differently, where the value and rate of change of $\mathrm{StO}_{2}$ compared to a phantom blood saturation reference will have a bias and different regression slope. One improvement in phantom design may include better optical spectral matching with human tissues for light attenuating components other than hemoglobin. Skin pigmentation and deeper tissue optical characteristics, which attenuate light more in the lower wavelengths $<750 \mathrm{~nm}$ [115] could be added to the phantoms, perhaps as a red dye, to better model these tissue optical characteristics. An ideal phantom would give the same quantitative value for the tissue oximeter parameter of interest (such as $\mathrm{StO}_{2}$ ) when measured by different manufacturer model monitors, corresponding to the same quantitative parameter value measured on human subjects. In the future, an in-vivo blood co-oximetry validated monitor "A" could be used to calibrate the ideal NIRS phantom, then this phantom can be used to calibrate and/or test monitors "B", "C" etc.

Tissue oximeter validation should be standardized so that in clinical use, $\mathrm{StO}_{2}$ measurements between tissue oximetry models are more consistent. Areas of standardization may include using a fixed mean blood volume ratio based on best available information for which we suggest using a blood volume V:A ratio of 70:30, use of highly accurate cooximeter models especially at lower oxygen saturation values for the reference measurements, and for adult subjects, use of a hypoxia protocol with good distribution of $\mathrm{FiO}_{2}$ levels while controlling $\mathrm{PaCO}_{2}$ levels to a limited range. A good distribution of skin tones from the different races are needed [83] as well as obtaining randomly a good distribution of subject background optical characteristics by having an effective sample size. If a liquid or other optical phantom can model all these parameters, then an alternative NIRS validation method may be available in the future.

For direct comparisons of NIRS tissue oximeter models, caution is advised in interpreting the results when no comparative co-oximetry blood oxygen saturation reference (such as REF CX) is used as a control. One cannot determine which monitor is more accurate or has the more appropriate $\mathrm{StO}_{2}$ value or rate of change [116] during an hypoxic or ischemia event without an appropriate comparative reference. Likewise, caution is advised in interpreting comparisons of different NIRS tissue oximeter models to blood oxygen saturation references different from that of the original NIRS tissue oximeter's validation reference such as cerebral $\mathrm{StO} 2$ vs central or mixed venous $\mathrm{SvO}_{2}$ [117-119]. Furthermore, results may not be comparable when the inappropriate sensor is applied outside the manufacturer's indications for use such as an adult validated sensor to an infant subject [120]. Both the $\mathrm{StO}_{2}$ value and the rate of change of $\mathrm{StO}_{2}$ to a physiological event will likely be inaccurate as the assumptions behind the sensor design and algorithm used will be different.
Ultimately, demonstrated clinical utility of NIRS tissue oximeters is important to gain acceptance for use in patient monitoring in healthcare systems. Relationships between $\mathrm{StO}_{2}$ and both physiological parameters and outcomes variables have been discussed elsewhere [121, 122]. Low $\mathrm{StO}_{2}$ values has been associated with post-op complications in aortic surgery [123], single lung ventilation [124, 125], beach chair shoulder procedures [126], and in cardiac surgery $[100,101,127] . \mathrm{StO}_{2}$ values provide guidance of setting ventilation controls particularly end tidal $\mathrm{CO}_{2}$ [103], setting safe ablation and entrainment mapping periods in ventricular tachycardia treatment [128], targeting oxygen saturation ranges to reduce risk of retinopathy in neonates [129], and catastrophic avoidance such as detection of misplaced cannulas and incorrect ventilation settings in surgery [130-132]. More interventional studies are needed to see if goal directed therapy based on $\mathrm{StO}_{2}$ can improve outcomes [121]. Standardized validation of tissue oximeters allows for better cross analysis of data between different manufacturer monitor models increase the potential of finding clinical correlations with disease states, corresponding outcomes, and determining possible interventions to improve outcomes.

In conclusion, we present the validation of the FORESIGHT ELITE tissue oximeter and the rationale behind the assumptions made in the protocol based on our experience with these monitors. We assumed that the cerebral and somatic invasive blood reference consisting of weighted tissue mean blood volume ratio (V:A) is 70:30 at $\mathrm{PaCO}_{2}$ of $37-40 \mathrm{mmHg}$ based on prior publications, and that this ratio is generally constant for healthy human subjects because of the high level of precision of tissue oximeter $\mathrm{StO}_{2}$ when compared to this invasive reference. We acknowledge that the V:A blood volume ratio normally varies in physiology and believe that monitoring $\mathrm{StO}_{2}$ is clinically important in part to show how the $\mathrm{V}$ :A ratio changes due to $\mathrm{CO}_{2}$ or other agents affecting tissue oxygenation. We believe that use of advanced statistical techniques such as Deming regression and bootstrap resampling to validate the best fit full data set model provides a more reliable representation of clinical performance over a wider range of subjects with different skin tones and background optical characteristics for a given sample size. Finally, we suggest standardization of tissue oximetry validation, whether in-vivo as presented, and/or invitro with an ideal NIRS phantom when perfected, so that tissue oximeters used in the clinic make more reliable measurements, with more consistency between different manufacturer tissue oximetry models, and therefore maximize overall utility of tissue oximetry in the clinic. 
Funding This research was partially funded by National Institutes of Health - National Institute of Neurological Disorders and Stroke (NIH NINDS) SBIR Grant NS045488.

\section{Compliance with ethical standards}

Conflict of interest Paul Benni is an employee and owns stock in CAS Medical Systems, Inc., the manufacturer of the FORE-SIGHT Elite NIRS monitor. Paul Benni is an inventor named on several patents relating to NIRS, but has no individual royalty rights (CAS Medical Systems own rights). David MacLeod received compensation for his work on this study through Duke University. Keita Ikeda received compensation for his work on this study through Duke University. Hung-Mo Lin received consultancy fee for statistical analysis.

Ethical approval All procedures performed in studies involving human participants were approved by The Duke University Health System Institutional Review Board for Clinical Investigations (DUHS IRB). DUHS IRB complies with all U.S. regulatory requirements related to the protection of human research participants. Specifically, the DUHS IRB complies with 45CFR46, 21CFR50, 21CFR56, 21CFR312, 21CFR812, and 45CFR164.508-514. In addition, the DUHS IRB complies with the Guidelines of the International Conference on Harmonization to the extent required by the U. S. Food and Drug Administration.

Informed consent Informed written consent was obtained from all study subjects.

Open Access This article is distributed under the terms of the Creative Commons Attribution 4.0 International License (http:// creativecommons.org/licenses/by/4.0/), which permits unrestricted use, distribution, and reproduction in any medium, provided you give appropriate credit to the original author(s) and the source, provide a link to the Creative Commons license, and indicate if changes were made.

\section{References}

1. McCormick PW, Stewart M, Goetting MG, Balakrishnan G. Regional cerebrovascular oxygen saturation measured by optical spectroscopy in humans. Stroke. 1991;22(5):596-602.

2. Pollard V, Prough DS, DeMelo AE, Deyo DJ, Uchida T, Stoddart HF. Validation in volunteers of a near-infrared spectroscope for monitoring brain oxygenation in vivo. Anesth Analg. 1996;82(2):269-77.

3. U.S. Food and Drug Administration (FDA) 510(k) Database http://www.accessdata.fda.gov/scripts/cdrh/cfdocs/cfpmn/pmn. cfm?ID=K960614.

4. U.S. Food and Drug Administration (FDA) 510(k) Database http://www.accessdata.fda.gov/scripts/cdrh/cfdocs/cfpmn/pmn. cfm?ID=K971628.

5. Henson LC, Calalang C, Temp JA, Ward DS. Accuracy of a cerebral oximeter in healthy volunteers under conditions of isocapnic hypoxia. Anesthesiology. 1998;88(1):58-65.

6. Shah N, Trivedi NK, Clack SL, Shah M, Shah PP, Barker S. Impact of hypoxemia on the performance of cerebral oximeter in volunteer subjects. J Neurosurg Anesthesiol. 2000;12(3):201-9.

7. Benni PB, Chen B, Dykes FD, Wagoner SF, Heard M, Tanner AJ, Young TL, Rais-Bahrami K, Rivera O, Short BL. Validation of the CAS neonatal NIRS system by monitoring
VV-ECMO patients: preliminary results. Adv Exp Med Biol. 2005;566:195-201.

8. Rais-Bahrami K, Rivera O, Short BL. Validation of a noninvasive neonatal optical cerebral oximeter in veno-venous ECMO patients with a cephalad catheter. J Perinatol. 2006;26(10):628-35.

9. MacLeod IARS abstract. 2006, http://www.iars.org/ assets/1/7/2006_Abstract_Supplement.pdf.

10. Ikeda K, MacLeod DB, Grocott HP, Moretti EW, Ames W, Vacchiano $C$. The accuracy of a near-infrared spectroscopy cerebral oximetry device and its potential value for estimating jugular venous oxygen saturation. Anesth Analg. 2014;119(6):1381-92.

11. Ito H, Kanno I, Iida H, Hatazawa J, Shimosegawa E, Tamura $\mathrm{H}$, Okudera T. Arterial fraction of cerebral blood volume in humans measured by positron emission tomography. Ann Nucl Med. 2001;15(2):111-6.

12. MacLeod DB, Ikeda K, Vacchiano C, Lobbestael A, Wahr JA, Shaw AD. Development and validation of a cerebral oximeter capable of absolute accuracy. J Cardiothorac Vasc Anesth. 2012;26(6):1007-14.

13. Kreeger RN, Ramamoorthy C, Nicolson SC, Ames WA, Hirsch R, Peng LF, Glatz AC, Hill KD, Hoffman J, Tomasson J, Kurth CD. Evaluation of pediatric near-infrared cerebral oximeter for cardiac disease. Ann Thorac Surg. 2012;94(5):1527-33.

14. Redford D, Paidy S, Kashif F. Absolute and trend accuracy of a new regional oximeter in healthy volunteers during controlled hypoxia. Anesth Analg. 2014;119(6):1315-9.

15. Franceschini MA, Boas DA, Zourabian A, Diamond SG, Nadgir S, Lin DW, Moore JB, Fantini S., Near-infrared spiroximetry: noninvasive measurements of venous saturation in piglets and human subjects. J Appl Physiol. 2002;92(1):372-84.

16. MacDonald MJ, Tarnopolsky MA, Green HJ, Hughson RL., Comparison of femoral blood gases and muscle near-infrared spectroscopy at exercise onset in humans, J Appl Physiol. 1999;86(2):687-93.

17. Soller BR, Soyemi O, Landry M, Shear M, Wu J, Hagan RD, Validation of a New NIRS Method for Measuring Muscle Oxygenation During Rhythmic Handgrip Exercise, http://ntrs.nasa. gov/archive/nasa/casi.ntrs.nasa.gov/20080029986.pdf.

18. U.S. Food and Drug Administration (FDA) 510(k) Database http://www.accessdata.fda.gov/scripts/cdrh/cfdocs/cfpmn/pmn. cfm?ID=K012759.

19. U.S. Food and Drug Administration (FDA) 510(k) Database http://www.accessdata.fda.gov/scripts/cdrh/cfdocs/cfpmn/pmn. cfm? ID =K042657.

20. U.S. Food and Drug Administration (FDA) 510(k) Database http://www.accessdata.fda.gov/scripts/cdrh/cfdocs/cfpmn/pmn. cfm?ID=K051274.

21. Kaufman J, Almodovar MC, Zuk J, Friesen RH. Correlation of abdominal site near-infrared spectroscopy with gastric tonometry in infants following surgery for congenital heart disease. Pediatr Crit Care Med. 2008;9(1):62-8.

22. McQuillen PS, Nishimoto MS, Bottrell CL, Fineman LD, Hamrick SE, Glidden DV, Azakie A, Adatia I, Miller SP. Regional and central venous oxygen saturation monitoring following pediatric cardiac surgery: concordance and association with clinical variables. Pediatr Crit Care Med. 2007;8(2):154-60.

23. U.S. Food and Drug Administration (FDA) 510(k) Database http://www.accessdata.fda.gov/scripts/cdrh/cfdocs/cfpmn/pmn. cfm?ID=K094030.

24. Pang CC. Measurement of body venous tone. J Pharmacol Toxicol Methods. 2000;44(2):341-60.

25. European Union Medical Device Directive (93/42/EEC) http://ec.europa.eu/consumers/sectors/medical-devices/files/ meddev/2_1_3__07-2001_en.pdf. 
26. Jöbsis FF., Noninvasive, infrared monitoring of cerebral and myocardial oxygen sufficiency and circulatory parameters. Science. 1977;198(4323):1264-7.

27. Elwell CE, Owen-Reece H, Cope M, Wyatt JS, Edwards AD, Delpy DT, Reynolds EO. Measurement of adult cerebral haemodynamics using near infrared spectroscopy. Acta Neurochir Suppl. 1993;59:74-80.

28. Wyatt JS., Noninvasive assessment of cerebral oxidative metabolism in the human newborn. J R Coll Physicians Lond. 1994;28(2):126-32.

29. du Plessis AJ. Near-infrared spectroscopy for the in vivo study of cerebral hemodynamics and oxygenation. Curr Opin Pediatr. 1995;7(6):632-9.

30. Wahr JA, Tremper KK, Samra S, Delpy DT, Near-infrared spectroscopy: theory and applications. J Cardiothorac Vasc Anesth. 1996;10(3):406-18.

31. Ferrari M, Mottola L, Quaresima V, Principles, techniques. and limitations of near infrared spectroscopy. Can J Appl Physiol. 2004;29(4):463-87.

32. Wolf M, Ferrari M, Quaresima V., Progress of near-infrared spectroscopy and topography for brain and muscle clinical applications. J Biomed Opt. 2007;12(6):062104. doi: $10.1117 / 1.2804899$

33. Marin T, Moore J, Understanding near-infrared spectroscopy. Adv Neonatal Care. 2011;11(6):382-8.

34. Delpy DT, Cope M, Q"uantification in tissue near-infrared spectroscopy. Phil Trans R Soc Lond B 1997;352:649-59.

35. Owen-Reece H, Smith M, Elwell CE, Goldstone JC. Near infrared spectroscopy. Br J Anaesth. 1999;82(3):418-26.

36. Rolfe P. In vivo near-infrared spectroscopy. Annu Rev Biomed Eng. 2000;2:715-54.

37. Cope M, Delpy DT, Reynolds EOR, Wray S, Wyatt J, Van der Zee P. Methods of quantitating cerebral near infrared spectroscopy data. Adv Exp Med Biol. 1988;222:183-9.

38. Strangman G, Boas DA, Sutton JP. Non-invasive neuroimaging using near-infrared light. Biol Psychiatry. 2002;52(7):679-93.

39. Strangman GE, Li Z, Zhang Q. Depth sensitivity and sourcedetector separations for near infrared spectroscopy based on the Colin27 brain template. PLoS ONE. 2013;8(8):e66319.

40. Germon TJ, Evans PD, Barnett NJ, Wall P, Manara AR, Nelson RJ. Cerebral near infrared spectroscopy: emitter-detector separation must be increased. Br J Anaesth. 1999;82(6):831-7.

41. Fukui Y, Ajichi Y, Okada E. Monte Carlo prediction of nearinfrared light propagation in realistic adult and neonatal head models. Appl Opt. 2003;42(16):2881-7.

42. Haeussinger FB, Heinzel S, Hahn T, Schecklmann M, Ehlis AC, Fallgatter AJ. Simulation of near-infrared light absorption considering individual head and prefrontal cortex anatomy: implications for optical neuroimaging. PLoS ONE. 2011;6(10):e26377.

43. Ohmae E, Ouchi Y, Oda M, Suzuki T, Nobesawa S, Kanno T, Yoshikawa E, Futatsubashi M, Ueda Y, Okada H, Yamashita Y. Cerebral hemodynamics evaluation by near-infrared time-resolved spectroscopy: correlation with simultaneous positron emission tomography measurements. Neuroimage. 2006;29(3):697-705.

44. Saager RB, Berger AJ. Direct characterization and removal of interfering absorption trends in two-layer turbid media. J Opt Soc Am A Opt Image Sci Vis. 2005;22(9):1874-82.

45. Saager RB, Telleri NL, Berger AJ. Two-detector Corrected Near Infrared Spectroscopy (C-NIRS) detects hemodynamic activation responses more robustly than single-detector NIRS. Neuroimage. 2011;55(4):1679-85.

46. Hirasawa A, Kaneko T, Tanaka N, Funane T, Kiguchi M, Sørensen H, Secher NH, Ogoh S. Near-infrared spectroscopy determined cerebral oxygenation with eliminated skin blood flow in young males. J Clin Monit Comput. 2016;30(2):243-50.

47. Umeyama S, Yamada T. Monte Carlo study of global interference cancellation by multidistance measurement of near-infrared spectroscopy. J Biomed Opt. 2009;14(6):064025.

48. Yamada T, Umeyama S, Matsuda K. Multidistance probe arrangement to eliminate artifacts in functional near-infrared spectroscopy. J Biomed Opt. 2009;14(6):064034.

49. Davie SN, Grocott HP. Impact of extracranial contamination on regional cerebral oxygen saturation: a comparison of three cerebral oximetry technologies. Anesthesiology. 2012;116(4):834-40.

50. Hirasawa A, Yanagisawa S, Tanaka N, Funane T, Kiguchi M, Sørensen H, Secher NH, Ogoh S. Influence of skin blood flow and source-detector distance on near-infrared spectroscopydetermined cerebral oxygenation in humans. Clin Physiol Funct Imaging. 2015;35(3):237-44.

51. Greenberg S, Murphy G, Shear T, Patel A, Simpson A, Szokol J, Avram MJ, Vender J. Extracranial contamination in the INVOS $5100 \mathrm{C}$ versus the FORE-SIGHT ELITE cerebral oximeter: a prospective observational crossover study in volunteers. Can J Anaesth. 2016;63(1):24-30.

52. Adeloye A, Kattan KR, Silverman FN. Thickness of the normal skull in the American Blacks and Whites. Am J Phys Anthropol. 1975;43(1):23-30.

53. Hwang K, Kim JH, Baik SH. The thickness of the skull in Korean adults. J Craniofac Surg. 1999;10(5):395-9.

54. Young RW. Age changes in the thickness of the scalp in white males. Hum Biol. 1959;31(1):74-9.

55. Chyu D, Hasan A, Pantin M, Chiricolo A, Pantin E. How deep is the brain? Anesth Analg 2013; 116(SCA Suppl):1182. (SCA45 abstract).

56. Davies D, Clancy M, Su Z, Denghani H, Belli A. Choosing a cerebral near-infrared spectroscopy system for use in traumatic brain injury: deriving the ideal source detector layout. Crit Care. 2014;18(Suppl 1):P468. (abstract).

57. Møller K, Paulson OB, Hornbein TF, Colier WN, Paulson AS, Roach RC, Holm S, Knudsen GM. Unchanged cerebral blood flow and oxidative metabolism after acclimatization to high altitude. J Cereb Blood Flow Metab. 2002 Jan;22(1):118-26.

58. Bain AR, Ainslie PN, Barak OF, Hoiland RL, Drvis I, Mijacika T, Bailey DM, Santoro A, DeMasi DK, Dujic Z, MacLeod DB. Hypercapnia is essential to reduce the cerebral oxidative metabolism during extreme apnea in humans. J Cereb Blood Flow Metab. 2017:271678x16686093.

59. Jakobsen M, Enevoldsen E. Retrograde catheterization of the right internal jugular vein for serial measurements of cerebral venous oxygen content. J Cereb Blood Flow Metab. 1989;9(5):717-20.

60. Goetting MG, Preston G. Jugular bulb catheterization: experience with 123 patients. Crit Care Med. 1990;18(11):1220-3.

61. Stocchetti N, Paparella A, Bridelli F, Bacchi M, Piazza P, Zuccoli P. Cerebral venous oxygen saturation studied with bilateral samples in the internal jugular veins. Neurosurgery. 1994;34(1):38-43. (discussion 43-4).

62. Stocchetti N, Magnoni S, Zanier ER. My paper 20 years later: cerebral venous oxygen saturation studied with bilateral samples in the internal jugular veins. Intensive Care Med. 2015;41(3):412-7.

63. Fandino J, Stocker R, Prokop S, Trentz O, Imhof HG. Cerebral oxygenation and systemic trauma related factors determining neurological outcome after brain injury. J Clin Neurosci. 2000;7(3):226-33.

64. Coplin WM, O'Keefe GE, Grady MS, Grant GA, March KS, Winn HR, Lam AM. Thrombotic, infectious, and procedural complications of the jugular bulb catheter in the intensive 
care unit. Neurosurgery. 1997;41(1):101-7. (discussion 107-9).

65. Schell RM, Cole DJ. Cerebral monitoring: jugular venous oximetry. Anesth Analg. 2000;90(3):559-66.

66. Macmillan CS, Andrews PJ. Cerebrovenous oxygen saturation monitoring: practical considerations and clinical relevance. Intensive Care Med. 2000;26(8):1028-36.

67. ht t p :// www.iso.org/iso/catalogue_detail. htm?csnumber $=51847$.

68. Bland JM, Altman DG. Statistical methods for assessing agreement between two methods of clinical measurement. The Lancet. 1986;1(8476):307-10.

69. Linnet K. Evaluation of regression procedures for methods comparison studies. Clin Chem. 1993;39(3):424-32.

70. Lin K, Lawrence I. A concordance correlation coefficient to evaluate reproducibility. Biometrics. 1989;45:255-68.

71. U.S. Food and Drug Administration (FDA) 510(k) Database http://www.accessdata.fda.gov/scripts/cdrh/cfdocs/cfpmn/ pmn.cfm?ID=K051257.

72. U.S. Food and Drug Administration (FDA) 510(k) Database http://www.accessdata.fda.gov/scripts/cdrh/cfdocs/cfpmn/ pmn.cfm?ID=K090807.

73. U.S. Food and Drug Administration (FDA) 510(k) Database http://www.accessdata.fda.gov/scripts/cdrh/cfdocs/cfpmn/ pmn.cfm?ID=K102715.

74. Linnet K. Estimation of the linear relationship between the measurements of two methods with proportional errors. Stat Med. 1990;9:pp. 1463-73.

75. Linnet K, Performance of Deming regression analysis in case of misspecified analytical error ratio in method comparison studies, Clin Chem 1998;44(5):pp. 1024-31.

76. Laird R, DerSimonian N. Meta-analysis in clinical trials. Control Clin Trials. 1986;7:177-88.

77. Fitzmaurice GM, Laird NM, Ware JH. Applied Longitudinal Analysis. New York: Wiley; 2004.

78. Carrasco JL \& Jover L, Estimating the Generalized Concordance Correlation Coefficient through Variance Components Biometrics, Vol. 59, No. 4 (Dec., 2003), pp. 849-58 Published by: International Biometric Society Stable http://www. jstor.org/stable/3695324.

79. Sherman M, le Cessie S. A comparison between bootstrap methods and generalized estimating equations for correlated outcomes in generalized linear models. Commun Statistics Simul Comput 1997;26:901-25.

80. Davison AC, Hinkley DV. Bootstrap methods and their applications. Cambridge UK: Cambridge University Press; 1997.

81. Wolf M, Naulaers G, van Bel F, Kleiser S, Griesen G, Review. A review of near infrared spectroscopy for term and preterm newborns. J Near Infrared Spectrosc. 2012;20:43-55. doi:10.1255/jnirs.972.

82. Watzman HM, Kurth CD, Montenegro LM, Rome J, Steven JM, Nicolson SC. Arterial and venous contributions to near-infrared cerebral oximetry. Anesthesiology. 2000;93(4):947-53.

83. U.S. Food and Drug Administration (FDA) Guidance http:// www.fda.gov/RegulatoryInformation/Guidances/ucm341718. htm.

84. U.S. Food and Drug Administration (FDA) 510(k) Database http://www.accessdata.fda.gov/scripts/cdrh/cfdocs/cfpmn/pmn. cfm? ID =K091452.

85. U.S. Food and Drug Administration (FDA) 510(k) Database http://www.accessdata.fda.gov/scripts/cdrh/cfdocs/cfpmn/pmn. $\mathrm{cfm} ? \mathrm{ID}=\mathrm{K} 143675$.

86. Brun NC, Moen A, Børch K, Saugstad OD, Greisen G. Nearinfrared monitoring of cerebral tissue oxygen saturation and blood volume in newborn piglets. Am J Physiol. 1997;273(2 Pt 2):H682-6.

87. An H, Lin W. Cerebral venous and arterial blood volumes can be estimated separately in humans using magnetic resonance imaging. Magn Reson Med. 2002;48(4):583-8.

88. Duong TQ, Kim SG. In vivo MR measurements of regional arterial and venous blood volume fractions in intact rat brain. Magn Reson Med. 2000;43(3):393-402.

89. Lee SP, Duong TQ, Yang G, Iadecola C, Kim SG. Relative changes of cerebral arterial and venous blood volumes during increased cerebral blood flow: implications for BOLD fMRI. Magn Reson Med. 2001;45(5):791-800.

90. An H, Lin W. Impact of intravascular signal on quantitative measures of cerebral oxygen extraction and blood volume under normo- and hypercapnic conditions using an asymmetric spin echo approach. Magn Reson Med. 2003;50(4):708-16.

91. Yezhuvath US, Lewis-Amezcua K, Varghese R, Xiao G, Lu H. On the assessment of cerebrovascular reactivity using hypercapnia BOLD MRI. NMR Biomed. 2009;22(7):779-86.

92. Murkin JM, Cerebral autoregulation. The role of $\mathrm{CO}_{2}$ in metabolic homeostasis. Semin Cardiothorac Vasc Anesth. 2007;11(4):269-73.

93. Xu F, Uh J, Brier MR, Hart J Jr, Yezhuvath US, Gu H, Yang $\mathrm{Y}, \mathrm{Lu} \mathrm{H}$. The influence of carbon dioxide on brain activity and metabolism in conscious humans. J Cereb Blood Flow Metab. 2011;31(1):58-67.

94. Mutch WA, Mandell DM, Fisher JA, Mikulis DJ, Crawley AP, Pucci O, Duffin J. Approaches to brain stress testing: BOLD magnetic resonance imaging with computer-controlled delivery of carbon dioxide. PLoS ONE. 2012;7(11):e47443.

95. Mutch WA, Patel SR, Shahidi AM, Kulasekara SI, Fisher JA, Duffin J, Hudson C. Cerebral oxygen saturation: graded response to carbon dioxide with isoxia and graded response to oxygen with isocapnia. PLoS ONE. 2013;8(2):e57881.

96. Park CS, Kwak JG, Lee C, Lee CH, Lee SK, Kim YL. Nearinfrared spectroscopy as a possible device for continuous monitoring of arterial carbon dioxide tension during cardiac surgery. Perfusion. 2011;26(6):524-8.

97. Tisdall MM, Taylor C, Tachtsidis I, Leung TS, Elwell CE, Smith M. The effect on cerebral tissue oxygenation index of changes in the concentrations of inspired oxygen and endtidal carbon dioxide in healthy adult volunteers. Anesth Analg. 2009;109(3):906-13.

98. Picton P, Chambers J, Shanks A, Dorje P., The influence of inspired oxygen fraction and end-tidal carbon dioxide on post-cross-clamp cerebral oxygenation during carotid endarterectomy under general anesthesia. Anesth Analg. 2010;110(2):581-7.

99. Denault A, Deschamps A, Murkin JM. A proposed algorithm for the intraoperative use of cerebral near-infrared spectroscopy. Semin Cardiothorac Vasc Anesth. 2007;11(4):274-81.

100. Murkin JM, Adams SJ, Novick RJ, Quantz M, Bainbridge D, Iglesias I, Cleland A, Schaefer B, Irwin B, Fox S. Monitoring brain oxygen saturation during coronary bypass surgery: a randomized, prospective study. Anesth Analg. 2007;104(1):51-8.

101. Deschamps A, Lambert J, Couture P, Rochon A, Lebon JS, Ayoub C, Cogan J, Denault A. Reversal of decreases in cerebral saturation in high-risk cardiac surgery. J Cardiothorac Vasc Anesth. 2013;27(6):1260-6.

102. Deschamps A, Hall R, Grocott H, Mazer CD, Choi PT, Turgeon AF, de Medicis E, Bussières JS, Hudson C, Syed S, Seal D, Herd S, Lambert J, Denault A, Deschamps A, Mutch A, Turgeon A, Denault A, Todd A, Jerath A, Fayad A, Finnegan B, Kent B, Kennedy B, Cuthbertson BH, Kavanagh B, Warriner B, MacAdams C, Lehmann C, Fudorow C, Hudson C, McCartney C, McIsaac D, Dubois D, Campbell D, Mazer D, Neilpovitz 
D, Rosen D, Cheng D, Drapeau D, Dillane D, Tran D, Mckeen D, Wijeysundera D, Jacobsohn E, Couture E, de Medicis E, Alam F, Abdallah F, Ralley FE, Chung F, Lellouche F, Dobson G, Germain G, Djaiani G, Gilron I, Hare G, Bryson G, Clarke $\mathrm{H}$, McDonald H, Roman-Smith H, Grocott H, Yang H, Douketis J, Paul J, Beaubien J, Bussières J, Pridham J, Armstrong JN, Parlow J, Murkin J, Gamble J, Duttchen K, Karkouti K, Turner K, Baghirzada L, Szabo L, Lalu M, Wasowicz M, Bautista M, Jacka M, Murphy M, Schmidt M, Verret M, Perrault MA, Beaudet N, Buckley N, Choi P, MacDougall P, Jones P, Drolet P, Beaulieu P, Taneja R, Martin R, Hall R, George R, Chun R, McMullen S, Beattie S, Sampson S, Choi S, Kowalski S, McCluskey S, Syed S, Boet S, Ramsay T, Saha T, Mutter T, Chowdhury T, Uppal V, Mckay W, Canadian Perioperative Anesthesia Clinical Trials Group. Cerebral oximetry monitoring to maintain normal cerebral oxygen saturation during highrisk cardiac surgery: a randomized controlled feasibility trial. Anesthesiology. 2016;124(4):826-36.

103. Murphy GS, Szokol JW, Avram MJ, Greenberg SB, Shear TD, Vender JS, Levin SD, Koh JL, Parikh KN, Patel SS. Effect of ventilation on cerebral oxygenation in patients undergoing surgery in the beach chair position: a randomized controlled trial. Br J Anaesth. 2014;113(4):618-27.

104. Esaki K, Hamaoka T, Rådegran G, Boushel R, Hansen J, Katsumura T, Haga S, Mizuno M. Association between regional quadriceps oxygenation and blood oxygen saturation during normoxic one-legged dynamic knee extension. Eur J Appl Physiol. 2005;95(4):361-70.

105. MacLeod D, Ikeda K. Simultaneous comparison of FORESIGHT and INVOS cerebral oximeters to jugular bulb and arterial co-oximetry measurements in healthy volunteers. Anesth Analg. 2009;108(SCA Suppl):SCA 56.

106. Bickler PE, Feiner JR, Rollins MD. Factors affecting the performance of 5 cerebral oximeters during hypoxia in healthy volunteers. Anesth Analg. 2013;117(4):813-23.

107. Janvier G, Guenard H, Lomenech AM. In vitro accuracy of three blood $\mathrm{O}_{2}$ saturation optic catheter systems. Intensive Care Med. 1994;20(7):480-3.

108. Liakopoulos OJ, Ho JK, Yezbick A, Sanchez E, Naddell C, Buckberg GD, Crowley R, Mahajan A. An experimental and clinical evaluation of a novel central venous catheter with integrated oximetry for pediatric patients undergoing cardiac surgery. Anesth Analg. 2007;105(6):1598-604.

109. Theory and Clinical Application of Continuous Fiberoptic Central Venous Oximetry (ScvO2) Monitoring: http://ht.edwards. $\mathrm{com} / \mathrm{scin} /$ edwards/sitecollectionimages/edwards/products/presep/ar04012presepwhitepaper.pdf.

110. Kleiser S, Nasseri N, Andresen B, Greisen G, Wolf M. Comparison of tissue oximeters on a liquid phantom with adjustable optical properties. Biomed Opt Exp. 2016;7(8):2973-92.

111. Hyttel-Sorensen S, Kleiser S, Wolf M, Greisen G. Calibration of a prototype NIRS oximeter against two commercial devices on a blood-lipid phantom. Biomed Opt Express. 2013;4(9):166272. doi:10.1364/BOE.4.001662.

112. Hull EL, Nichols MG, Foster TH. Quantitative broadband nearinfrared spectroscopy of tissue-simulating phantoms containing erythrocytes. Phys Med Biol. 1998;43(11):3381-404.

113. Suzuki S, Takasaki S, Ozaki T, and Kobayashi Y, A Tissue Oxygenation Monitor using NIR Spatially Resolved Spectroscopy, Part of the SPIE Conference on Optical Tomography and Spectroscopy of Tissue III, San Jose, California, January 1999 SPIE Vol. 3597:582-92; 0277-786X/991.

114. Hallacoglu B, Sassaroli A, Fantini S, Optical characterization of two-layered turbid media for non-invasive. Absolute oximetry in cerebral and extracerebral tissue. PLoS ONE. 2013;8(5):e64095. doi:10.1371/journal.pone.0064095.
115. Jacques SL. Optical properties of biological tissues: a review. Phys Med Biol. 2013;58:R37-61.

116. Tomlin KL, Neitenbach AM, Borg U. Detection of critical cerebral desaturation thresholds by three regional oximeters during hypoxia: a pilot study in healthy volunteers. BMC Anesthesiol. 2017;17(1):6

117. Moerman A, Vandenplas G, Bové T, Wouters PF, De Hert SG. Relation between mixed venous oxygen saturation and cerebral oxygen saturation measured by absolute and relative near-infrared spectroscopy during off-pump coronary artery bypass grafting. Br J Anaesth. 2013;110(2):258-65.

118. Ricci Z, Garisto C, Favia I, Schloderer U, Giorni C, Fragasso T, Picardo S. Cerebral NIRS as a marker of superior vena cava oxygen saturation in neonates with congenital heart disease. Paediatr Anaesth. 2010;20(11):1040-5.

119. Skowno J. Correlating cerebral NIRS and superior vena cava ScvO2 in pediatrics. Paediatr Anaesth. 2011;21(4):463.

120. Dix LM, van Bel F, Baerts W, Lemmers PM. Comparing nearinfrared spectroscopy devices and their sensors for monitoring regional cerebral oxygen saturation in the neonate. Pediatr Res. 2013;74(5):557-63.

121. Bickler P, Feiner J, Rollins M, Meng L. Tissue oximetry and clinical outcomes. Anesth Analg. 2017;124(1):72-82.

122. Heller JA, DeMaria S Jr, Govindaraj S, Lin HM, Fischer GW, Evans A, Weiner MM. Cerebral oximetry monitoring during sinus endoscopy. Laryngoscope. 2015;125(4):E127-31.

123. Fischer GW, Lin HM, Krol M, Galati MF, Di Luozzo G, Griepp RB, Reich DL. Noninvasive cerebral oxygenation may predict outcome in patients undergoing aortic arch surgery. $\mathrm{J}$ Thorac Cardiovasc Surg. 2011;141(3):815-21.

124. Kazan R, Bracco D, Hemmerling TM. Reduced cerebral oxygen saturation measured by absolute cerebral oximetry during thoracic surgery correlates with postoperative complications. Br J Anaesth. 2009;103(6):811-6.

125. Tang L, Kazan R, Taddei R, Zaouter C, Cyr S, Hemmerling TM. Reduced cerebral oxygen saturation during thoracic surgery predicts early postoperative cognitive dysfunction. $\mathrm{Br} \mathrm{J}$ Anaesth. 2012;108(4):623-9.

126. Murphy GS, Szokol JW, Marymont JH, Greenberg SB, Avram MJ, Vender JS, Vaughn J, Nisman M. Cerebral oxygen desaturation events assessed by near-infrared spectroscopy during shoulder arthroscopy in the beach chair and lateral decubitus positions. Anesth Analg. 2010;111(2):496-505.

127. Trinh M, Uysal S, Fischer G, Lin H, Reich D, Optimizing cerebral saturation in cardiac surgical patients, Anesth Analg. 2016;122:S-79.

128. Miller MA, Dukkipati SR, Mittnacht AJ, Chinitz JS, Belliveau L, Koruth JS, Gomes JA, d'Avila A, Reddy VY. Activation and entrainment mapping of hemodynamically unstable ventricular tachycardia using a percutaneous left ventricular assist device. J Am Coll Cardiol. 2011;58(13):1363-71.

129. Vesoulis ZA, Lust CE, Liao SM, Trivedi SB, Mathur AM. Early hyperoxia burden detected by cerebral near-infrared spectroscopy is superior to pulse oximetry for prediction of severe retinopathy of prematurity. J Perinatol. 2016;36(11):966-71.

130. Faulkner JT, Hartley M, Tang A. Using cerebral oximetry to prevent adverse outcomes during cardiac surgery. Perfusion. 2011;26(2):79-81.

131. Fischer GW. Recent advances in application of cerebral oximetry in adult cardiovascular surgery. Semin Cardiothorac Vasc Anesth. 2008;12(1):60-9.

132. Fischer GW, Stone ME. Cerebral air embolism recognized by cerebral oximetry. Semin Cardiothorac Vasc Anesth. 2009;13(1):56-9. 